\title{
Dynamic Strain Aging Phenomena and Tensile Response of Medium-Mn TRIP Steel
}

\author{
DANIEL M. FIELD and DAVID C. VAN AKEN
}

Dynamic strain aging (DSA) and rapid work hardening are typical behaviors observed in medium-Mn transformation-induced plasticity (TRIP) steel. Three alloys with manganese ranging from 10.2 to $13.8 \mathrm{wt}$ pct with calculated room temperature stacking fault energies varying from -2.1 to $0.7 \mathrm{~mJ} / \mathrm{m}^{2}$ were investigated. Significant serrations were observed in the stress-strain behavior for two of the steels and the addition of $4.6 \mathrm{wt}$ pct chromium was effective in significantly reducing the occurrence of DSA. Addition of chromium to the alloy reduced DSA by precipitation of $\mathrm{M}_{23}(\mathrm{C}, \mathrm{N})_{6}$ during batch annealing at $873 \mathrm{~K}\left(600{ }^{\circ} \mathrm{C}\right)$ for 20 hours. Three distinct DSA mechanisms were identified: one related to manganese ordering in stacking faults associated with $\varepsilon$-martensite and austenite interface, with activation energies for the onset and termination of DSA being 145 and $277 \mathrm{~kJ} / \mathrm{mol}$. A second mechanism was associated with carbon diffusion in $\gamma$-austenite where $\mathrm{Mn}-\mathrm{C}$ bonding added to the total binding energy, and activation energies of 88 and $155 \mathrm{~kJ} / \mathrm{mol}$ were measured for the onset and termination of DSA. A third mechanism was attributed to dislocation pinning and unpinning by nitrogen in $\alpha$-ferrite with activation energies of 64 and $123 \mathrm{~kJ} / \mathrm{mol}$ being identified. Tensile behaviors of the three medium manganese steels were studied in both the hot band and batch annealed after cold working conditions. Ultimate tensile strengths ranged from 1310 to $1404 \mathrm{MPa}$ with total elongation of 24.1 to 34.1 pct. X-ray diffraction (XRD) was used to determine the transformation response of the steels using interrupted tensile tests at room temperature. All three of the processed steels showed evidence of two-stage TRIP where $\gamma$-austenite first transformed to $\varepsilon$-martensite, and subsequently transformed to $\alpha$-martensite.

https://doi.org/10.1007/s11661-018-4481-y

(C) The Minerals, Metals \& Materials Society and ASM International 2018

\section{INTRODUCTION}

MEDIUM manganese steels are of interest for automotive sheet steel, since they can be processed by cold working and intercritical or batch annealing. The resulting grain structures can be submicron with yield strengths in excess of $800 \mathrm{MPa}$ as will be shown in this study. These medium manganese alloys are considered 3rd generation advanced high strength steel with strength and ductility combinations meeting or exceeding goals set by the Department of Energy, defined as strengths of 1200 to $1500 \mathrm{MPa}$ and associated total elongations of 30 to 25 pct. However, many of these medium-Mn steels exhibit static strain aging that is manifested by yield point behavior and yield point elongations that contribute to the overall total elongations. ${ }^{[1-13]}$ Medium manganese steels can also be

DANIEL M. FIELD and DAVID C. VAN AKEN are with the Department of Materials Science and Engineering, Missouri University of Science and Technology Rolla, MO 65409. Contact e-mail: dcva@mst.edu

Manuscript submitted September 22, 2017.

Article published online January 31, 2018 formulated to produce rapid work hardening as a result of two-stage transformation-induced plasticity (TRIP), but many of these alloys exhibit dynamic strain aging (DSA) and a reduced total elongation to failure, with failure occurring prior to necking.

\section{A. Static Strain Aging}

Yield point elongation (YPE), associated with static strain aging and the formation of Lüders bands, is undesirable when forming complex automotive parts. ${ }^{[14]}$ Inhomogeneous deformation associated with YPE are deleterious to press forming and leads to inconsistencies in the thickness of the final parts. Static strain aging is characterized by an increase in yield and ultimate strengths, a decrease in the total elongation, and a time-dependent return of the YPE or Lüders strain after plastic deformation. ${ }^{[15,16]}$ Baird and Jamieson showed that the addition of $\mathrm{N}$ will have a strong effect on the occurrence of static strain aging in ferritic steels. ${ }^{[17]}$ Many of the medium manganese (5 to $10 \mathrm{wt}$ pct $)^{[2,3,5-12,18]}$ steels proposed for 3rd generation advanced high strength steel application exhibit YPE, and it is noted that the degree of YPE can range from 2 
to 10 pet depending upon chemistry and processing prior to mechanical testing. Work by Suh et al. ${ }^{[3]}$ on three $\mathrm{Fe}-0.5 \mathrm{Si}-5 \mathrm{Mn}-2 \mathrm{Al}$ (wt pct) alloys with carbon contents (0.06 to $0.11 \mathrm{wt}$ pct) exhibited varying degrees of YPE that was dependent upon heat treatment. They observed that an increase in heat treatment temperature from $993 \mathrm{~K}$ to $1033 \mathrm{~K}\left(720{ }^{\circ} \mathrm{C}\right.$ to $\left.760{ }^{\circ} \mathrm{C}\right)$ leads to a change in YPE from 10 to 4 pct strain for all three alloys independent of carbon content. This significant change in the YPE was not discussed by Suh et al., but is potentially attributed to the volume fraction of $\alpha$-ferrite/martensite in the microstructure. Specimens with 10 pct YPE had 87 vol pct $\alpha$-ferrite as compared to the 4 pct YPE specimens with 72 vol pct ferrite. Work by Han et $a{ }^{\left[{ }^{[9]}\right.}$ on a medium-Mn steel (8.5 wt pct Mn) showed an extensive yield point elongation (11 pct) after cold working and intercritical annealing at $893 \mathrm{~K}\left(620{ }^{\circ} \mathrm{C}\right)$, and this steel contained $63 \mathrm{vol}$ pct $\alpha$-ferrite/martensite in the starting structure. Steineder et al.'s investigation of processing routes on a Fe-6Mn-0.1C (wt pct) alloy revealed that grain morphology, size, and $\gamma$-austenite stability of medium-Mn steels can influence the extent of yield point elongation. ${ }^{[18]}$ It was noted by Steineder et al. that the YPE was influenced by the volume fraction of $\alpha$-ferrite. Specimens with the highest $\alpha$-ferrite content, independent of grain morphology, exhibited the greatest yield point elongation and this is consistent with what was described in the previously presented works.

\section{B. Dynamic Strain Aging}

An increased work hardening rate, negative strain rate dependence, and serrated stress-strain curves are often associated with DSA, which is also described as the Portevin-Le Chatelier (PLC) effect. It was noted by Horvath et al. ${ }^{[14]}$ that the negative strain-rate dependence on ultimate tensile strength of the medium-Mn steels is a concern for the crash worthiness of potential future $3^{\text {rd }}$ generation advanced high strength steels. For ferritic steels that show DSA, Baird and Jamieson ${ }^{[17]}$ attribute a reduction in the uniform elongation to exhaustion of interstitial solute that leads to a localized site of plastic flow and initiation of local necking. The dynamic interaction of dislocations and point defects during DSA occurs when dislocations are pinned by interstitials during plastic deformation causing a reduction in mobile dislocation density that results in an increase in flow stress as fewer dislocations must move faster to accommodate the imposed strain rate. Dislocation multiplication or subsequent unpinning at the higher stress will produce a transient drop in the flow stress, since more dislocations are mobile and move at a slower velocity to accommodate the imposed strain rate. Work by Rodriguez on DSA identified five unique forms of serrated flow observed in steel and are schematically shown in Figure 1. ${ }^{[19]}$

The most comprehensive work performed on DSA in medium manganese steel has been on Hadfield's manganese stee ${ }^{[20]}$ and steels that exhibit twining-induced plasticity (TWIP). ${ }^{[21]}$ Dastur and Leslie investigated the work hardening mechanism of a $0.2 \mathrm{Si}-11.4 \mathrm{Mn}-0.17-$ Ni-0.16Cr-0.08Mo-1.13C-balFe (in wt pet) Hadfield steel and argued that the work hardening behavior of Hadfield steel was related to dynamic strain aging and not twin formation. They determined the activation energy for the onset and termination of DSA to be 104 and $146 \mathrm{~kJ} / \mathrm{mol},{ }^{[20]}$ and showed for the onset of DSA that the activation energy was below the activation energy for $\mathrm{C}$ diffusion in $\gamma$-austenite $\left(\sim 134 \mathrm{~kJ} / \mathrm{mol}^{[20]}\right)$ Lee et al. investigated the dynamic strain aging of two TWIP steels, one containing aluminum, $18 \mathrm{Mn}-$ 1.5Al-0.6C-BalFe (wt pct), and the second being an Al-free 18Mn-0.6C-balFe (wt pct) steel. Both steels exhibited varying levels of DSA and an activation energy of $100 \mathrm{~kJ} / \mathrm{mol}$ was determined by internal friction. Mössbauer spectroscopy was used to identify the defect complex responsible for pinning. From these results, they proposed that the mechanism was related to the diffusion of carbon, or a point defect complex, to the stacking fault region. ${ }^{[21]}$ It is interesting to note that both investigations measured very similar activation energies; however, the measured energy value is well below the activation energy for diffusion of $\mathrm{C}$ (134 $\mathrm{kJ} / \mathrm{mol}$ ) in $\gamma$-Fe. The work by Balluff ${ }^{[22]}$ concluded that for diffusion within a dislocation core the required energy was 0.4 to 0.7 of bulk diffusion, and both sets $^{[20,21]}$ of data are 0.75 to 0.77 of pure lattice diffusion of $\mathrm{C}$ in $\gamma$-austenite. Furthermore, $\mathrm{Mn}$ is expected to partition to the stacking fault lowering the fault energy and partitioning of $\mathrm{Mn}$ to the fault has been shown experimentally by the work of Kuzmina et al. ${ }^{[23]}$ Conversely $\mathrm{C}$ will increase the fault energy if at the fault plane. Work by Medvedeva et al. ${ }^{[24]}$ showed by first principle calculations that $\mathrm{Mn}$ and $\mathrm{C}$ form a dipole along $<100>$ in both bcc and fcc iron. According to Medvedeva et al. in the presence of $\mathrm{Mn}$ a $\mathrm{Mn}-\mathrm{C}$ pair forms that reduces the expected increase in the fault energy that is caused by $\mathrm{C}$ alone. ${ }^{[25]}$

Dynamic strain aging is a common observation in medium-Mn steels ${ }^{[4,5,7,10,12,26-30]}$ with a wide variation in processing. Gibbs et al. ${ }^{[10]}$ investigated a $7 \mathrm{Mn}$ steel annealed at temperatures varying from $848 \mathrm{~K}$ to $948 \mathrm{~K}$ $\left(575^{\circ} \mathrm{C}\right.$ to $\left.675^{\circ} \mathrm{C}\right)$ for 168 hours. The investigated steel contained greater than 60 vol pct $\alpha$-ferrite/martensite and the specimens examined exhibited either static or dynamic strain aging or both in the observed tensile responses. The $898 \mathrm{~K}$ and $873 \mathrm{~K}\left(625^{\circ} \mathrm{C}\right.$ and $\left.600{ }^{\circ} \mathrm{C}\right)$ conditions exhibited both a DSA and YPE behavior, and both contained $\geq 67$ vol pet $\alpha$-ferrite/martensite in the starting structure. It is interesting to note in the $898 \mathrm{~K}(625$ ${ }^{\circ} \mathrm{C}$ ) annealed condition there is a high work hardening rate $(n \approx 0.5)$ as well as a Type B DSA tensile response. Gibbs et al. showed in XRD analysis that there was $\varepsilon$-martensite formation in the partially strained $898 \mathrm{~K}$ annealed alloy's microstructure after 3.7 pet strain. The $873 \mathrm{~K}\left(600{ }^{\circ} \mathrm{C}\right)$ condition exhibits a reduced DSA response and a lower work hardening rate $(n \approx 0.4)$; there is also an associated increase of the YPE by 2 pet strain. The cause for the change in the DSA and YPE was not addressed by the authors; however, an increase in $\alpha$-ferrite/martensite content in the starting structure is again a potential explanation. An alloy previously investigated by the authors ${ }^{[12]}$ is a medium-Mn two-stage TRIP steel (11.5Mn-0.38Al-0.11C-2.46Si-0.029N-balFe.) that 


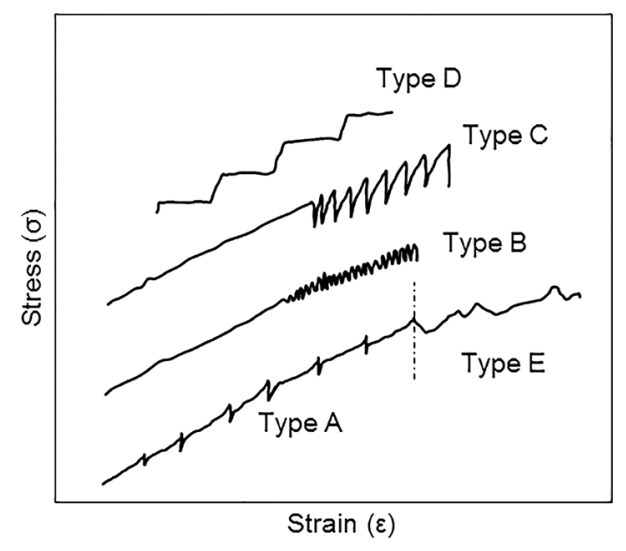

Fig. 1-The five types of serrated flow reported in literature. Type A where deformation bands initiate at the same end of the specimen and propagate in the same direction. Type B occurs due to discontinuous band propagation. Type $\mathrm{C}$ are yield drops due to dislocation unlocking and typically occurs at higher temperature. Type D are described as Lüders bands with no work hardening. Type E are Type A serrations at higher strains.

had significant serrations associated with DSA, a high work hardening rate $(\mathrm{n} \approx 0.6)$ and exhibited $\varepsilon$-martensite in the initial structure with 40 vol pct $\alpha$-ferrite/martensite.

Many medium-Mn TRIP alloys contain significant levels (> $100 \mathrm{ppm})$ of nitrogen, ${ }^{[7,12]}$ which can also contribute to DSA. Zhang et al. ${ }^{[7]}$ reports a medium-Mn steel with $120 \mathrm{ppm}$ nitrogen that exhibited significant DSA at room temperature after varying degrees of intercritical warm working ( 0 to 77.5 pct reduction in thickness) at $923 \mathrm{~K}\left(650{ }^{\circ} \mathrm{C}\right)$. All of the reported specimens exhibit significant Type A and B serrations, and the authors note that the average strain hardening exponent of $n \approx 0.36$ was unchanged for each condition tested. Zhang et al. stated that each steel in the warm worked condition contained $\sim 70$ vol pet $\alpha$-ferrite/martensite. The work by Shi et al. ${ }^{[4]}$ studied four medium $\mathrm{Mn}$ alloys annealed at $923 \mathrm{~K}\left(650^{\circ} \mathrm{C}\right)$. All four of the alloys contained $>0.2 \mathrm{wt}$ pct carbon and exhibited significant Type B serrations in the stressstrain data. Zhang et al. reports that the starting structure of the investigated steels was primarily $\alpha$-ferrite (67 vol pct) with the remainder of the microstructure being $\gamma$-austenite. Recent works ${ }^{[27-30]}$ with medium-Mn steels on the PLC effect have shown that there is a strain-induced transformation of $\gamma$-austenite to $\alpha$-martensite within the PLC band. This effect is attributed to the high localized plastic deformation leading to the strain induced transformation of $\gamma \rightarrow \alpha$-martensite. These works however all describe steels containing $>50 \mathrm{vol}$ pct $\alpha$-ferrite in the starting condition as well as a significant YPE behavior. Work by Luo et al. ${ }^{[5]}$ investigated two alloys with varying heat treatment temperatures with DSA being observed in the alloys heat treated to $943 \mathrm{~K}\left(670{ }^{\circ} \mathrm{C}\right)$; these steels contained roughly 88 vol pct $\alpha$-ferrite. However, alloys heat treated at 923 $\mathrm{K}\left(650{ }^{\circ} \mathrm{C}\right)$ did not exhibit any serrations and it was noted by TEM analysis that cementite had precipitated in these specimens.

\section{Microstructural Features to Control DSA}

Additions of carbides, nitrides, or complex carbo-nitrides can be utilized to alter the DSA response of alloys. For ferritic grades of steel, the formation of a carbide can act as a sink for $\mathrm{C}$ and subsequently reduces the appearance of DSA. ${ }^{[31-34]}$ Vankadesan et al..$^{[35]}$ observed that increasing the Ti: $(\mathrm{C}, \mathrm{N})$ ratio from 3.6 to 5.3 lead to an increase in the activation energy for the onset of DSA from 85 to $121 \mathrm{~kJ} / \mathrm{mol}$. The work of Cuddy and Leslie $^{[36]}$ showed that for ferritic steels containing 0.005 wt pct $\mathrm{C}$ the addition of $0.44 \mathrm{wt}$ pct Ti lead to a higher temperature range at which DSA was observed. Cuddy and Leslie noted that the temperature range for DSA in Ti containing Fe-Ni alloys was $673 \mathrm{~K}$ to $773 \mathrm{~K}\left(400{ }^{\circ} \mathrm{C}\right.$ to $500{ }^{\circ} \mathrm{C}$ ). In the non-Ti bearing $\mathrm{Fe}-\mathrm{Ni}$ steel, DSA was observed at a temperature range of $473 \mathrm{~K}$ to $523 \mathrm{~K}$ (200 ${ }^{\circ} \mathrm{C}$ to $\left.250{ }^{\circ} \mathrm{C}\right) \cdot{ }^{[36]}$ Baird and Jamieson ${ }^{[17]}$ used wet hydrogen to remove nitrogen from non-Ti containing steel and the denitriding eliminated the DSA. Aluminum additions have also been shown to remove DSA in TWIP steels. ${ }^{[37,38]}$ The effect of aluminum in TWIP steel is reported to be due to its effect on the intrinsic stacking fault (ISF) energy. Aluminum has been shown to increase the ISF by $11.3 \mathrm{~mJ} / \mathrm{m}^{2}$ with a $1.5 \mathrm{wt}$ pct increase in aluminum ${ }^{[38]}$ as determined from stacking fault widths measured using transmission electron microscopy (TEM). The observed narrowing of the stacking fault width was assumed to reduce the interaction with the point defect complex leading to a loss of the dynamic pinning effect as proposed by Kim et al. ${ }^{[38]}$ A relationship of the activation energy for serrated yielding has been derived by McCormick ${ }^{[39]}$ and Sleeswyk ${ }^{[40]}$ from a static strain aging model as shown in Eq. [1].

$$
\varepsilon_{C}^{m+\beta}=\frac{\left[\left(\frac{C_{1}}{\alpha C_{0}}\right)^{\frac{3}{2}} * \dot{\varepsilon} * k T b \exp \left(\frac{Q_{\mathrm{m}}}{k T}\right)\right]}{3 L N_{\mathrm{d}} K_{\mathrm{v}} U_{\mathrm{m}} D_{0}}
$$

where $C_{1}$ is the solute concentration at the dislocation needed to lock it; $C_{0}$ is the original solute concentration in the alloy; $\alpha$ is a constant; $Q_{\mathrm{m}}$ is the activation energy for solute migration; $L$ is the obstacle spacing; $U_{\mathrm{m}}$ is the binding energy between solute and dislocation; $D_{0}$ is the diffusion coefficient; $k$ is Boltzmann constant; $T$ is temperature and $b$ is the burgers vector. Parameters $K_{\mathrm{v}}$, $m, N_{\mathrm{d}}$, and $\beta$ are related to the strain dependency of vacancy concentration; $\dot{\varepsilon}$ is the strain rate, and $\epsilon_{\mathrm{c}}$ is the critical strain where serrations occur. A reduction in $C_{0}$, where $C_{0}$ describes the solute in solution, such as nitrogen in ferrite, will lead to greater activation energy.

In the study presented here, the activation energy for onset and termination of DSA is studied in two Mn alloys; one predominately ferritic and one predominately austenitic. A third alloy being formulated to reduce the contribution of nitrogen to DSA by the precipitation of a carbo-nitride. Chromium was chosen, since it readily forms a carbo-nitride such as $\mathrm{Cr}_{23}(\mathrm{C}, \mathrm{N})_{6}$ and first principle calculations by Limmer et al. ${ }^{[41]}$ showed promising results with respect to the effect of $\mathrm{Cr}$ on the stacking fault energy; Cr lowers the unstable stacking 
fault (USF) energy $39 \mathrm{~mJ} / \mathrm{m}^{2}$ per 4 at. pet $\mathrm{Cr}$ addition, and increases (less than most other alloy additions) the ISF. According to the first principles calculations, chromium increases the ISF by $14 \mathrm{~mJ} / \mathrm{m}^{2}$ per 4 at. pct. Chromium should therefore behave in a similar fashion to aluminum which adds $18 \mathrm{~mJ} / \mathrm{m}^{2}$ per 4 at. pet. Field et al. ${ }^{[42]}$ showed that $\mathrm{Cr}$ has a similar effect on both the $\mathrm{Ms}^{\varepsilon}$ and $\mathrm{Ms}^{\alpha}$ as aluminum.

Formulation of the chromium bearing steel in this investigation was performed using the thermodynamic optimization software FactSage $7.0^{\mathrm{TM}}$ with the FSstel database. Figure 2 shows the phase stability for the Fe-0.15C-12Mn-1Si-4.5Cr-0.025N (wt pct) steel as a function of temperature. Precipitation of $2.8 \mathrm{wt}$ pct $\mathrm{M}_{23}(\mathrm{C}, \mathrm{N})_{6}$ at equilibrium is predicted for a subcritical temperature (batch annealing) at $873 \mathrm{~K}\left(600{ }^{\circ} \mathrm{C}\right)$.

\section{EXPERIMENTAL PROCEDURE}

Three alloys were used in this investigation and were produced by coreless induction melting of induction iron, ferrosilicon, electrolytic manganese, pure aluminum, ferrochrome, and carbon in the form of graphite. An argon cover gas was used to shield the melt and calcium wire additions were made to modify oxide inclusions and remove sulfur. Castings were poured into a ladle modified with a ceramic dam to force liquid from below the surface to form the pouring stream in a manner similar to a teapot. All alloys were cast with $150 \mathrm{~K}\left(150 \mathrm{C}^{\circ}\right)$ superheat into phenolic no-bake sand molds to form a Y-block with dimensions measuring $12.6 \times 6 \times 1.7 \mathrm{~cm}^{3}$. A Foseco KALPUR insulated riser with a diameter of $13.5 \mathrm{~cm}$ and height of $15.3 \mathrm{~cm}$ was attached to the upper Y-portion of the casting to act as a riser and ensure the soundness of the Y-block casting. Chemical analyses were obtained by ion coupled plasma spectrometry after sample dissolution in hydrochloric and nitric acid. Carbon and nitrogen contents were determined by combustion using a LECO CS6000 and a LECO TC500, respectively. Alloy composition, stacking fault energy, and martensite start temperatures are listed in Table I for a fully austenitic and homogeneous alloy. Alloys are designated by the nominal Mn content of the steel. The martensite

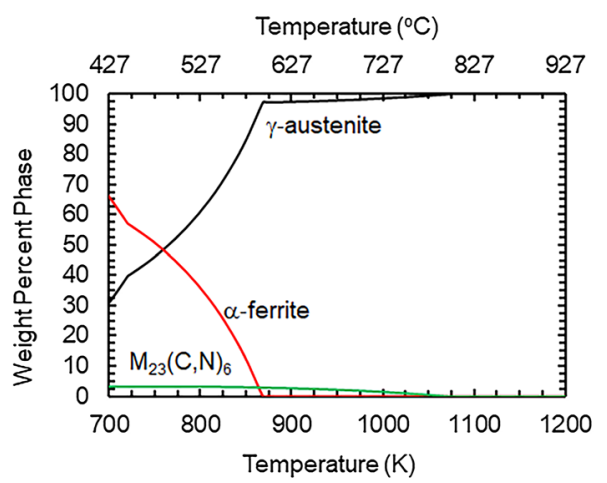

Fig. 2-Phase fraction as a function of temperature for a Fe-0.15C-12Mn-1Si-4.5Cr-0.025N steel. start temperatures were calculated according to the work of Pisarik and Van Aken ${ }^{[43]}$ for $\varepsilon$-martensite, and Field et al. ${ }^{[42]}$ for $\alpha$-martensite. Stacking fault energy (SFE) was calculated according to the original work by Olson and Cohen ${ }^{[44]}$ using Eq. [2] with a value of $n=2$ for the planar fault thickness.

$$
\operatorname{SFE}\left(\mathrm{mJ} / \mathrm{m}^{2}\right)=n \rho\left(\Delta G^{\gamma \rightarrow \varepsilon}\right)+2 \sigma^{\gamma / \varepsilon}
$$

A regular solution model ${ }^{[43]}$ was used to calculate the driving force for transformation, $\Delta G^{\gamma \rightarrow \varepsilon}$; Vegard's law was used to calculate the planar atomic density, $\rho$, of $\{111\}$, and the interfacial energy between the $\gamma$-austenite and $\varepsilon$-martensite, $\sigma^{\gamma / \varepsilon}$, was held constant at $10 \mathrm{~mJ} / \mathrm{m}^{2}$. The start temperature for the $\varepsilon$-martensite was calculated by determining the temperature at which $\mathrm{SFE}=0$ $\mathrm{mJ} / \mathrm{m}^{2}$ for the case where $n=4 .^{[43]}$ The $M_{\mathrm{S}}^{\alpha}$ was calculated according to the work by Field et al., ${ }^{[42]}$ where the strain energy of transformation, $\left(\Delta G_{\mathrm{str}}^{\gamma \rightarrow \alpha}\right)$ was balanced against the chemical driving force $\left(\Delta G_{\text {chem }}^{\gamma \rightarrow \alpha}\right)$ according to Eqs. [3] and [4].

$$
\begin{gathered}
\Delta G_{\mathrm{str}}^{\gamma \rightarrow \alpha}+\Delta G_{\text {chem }}^{\gamma \rightarrow \alpha}=0 \\
\Delta G_{\mathrm{str}}(\mathrm{J} / \mathrm{mol})=E \Omega \delta^{2}(14.8-0.12 T),
\end{gathered}
$$

where $\Delta G_{\text {chem }}^{\gamma \rightarrow \alpha}$ is calculated according to a modified regular solution model described by Field et al ${ }^{[42]} \Omega$ is the molar volume for iron of $7.15 \times 10^{-6}\left(\mathrm{~m}^{3} / \mathrm{mol}\right) ; \delta$ is the lattice misfit between the $\gamma$-austenite and $\alpha$-martensite with an approximate strain of $1.11 \times 10^{-2}(\mathrm{~m} / \mathrm{m}) ; \mathrm{T}$ is the temperature in Kelvin and $\mathrm{E}$ is the modulus in units of $\mathrm{Pa}$. The start temperature for the $\alpha$-martensite was calculated by determining the temperature where Eq. [3] is true. Negative stacking fault energies reported in Table I indicate that hexagonal iron is more stable than austenite at room temperature.

Steel castings were normalized at $1373 \mathrm{~K}\left(1100{ }^{\circ} \mathrm{C}\right)$, held at temperature for 2 hours, and air-cooled to ambient $298 \mathrm{~K}\left(25^{\circ} \mathrm{C}\right)$. Castings were milled to an orthogonal prism of dimensions $15.5 \times 125 \times 50 \mathrm{~mm}^{3}$ and hot rolled sequentially by heating to $1223 \mathrm{~K}(950$ $\left.{ }^{\circ} \mathrm{C}\right)$, rolling, and reheating to $1223 \mathrm{~K}\left(950{ }^{\circ} \mathrm{C}\right)$. This was repeated to obtain the desired hot band gage of $2.5 \mathrm{~mm}$, which accomplished a total hot reduction of $87.2 \pm 6.8$ pct. Samples exited the rolling mill at $1048 \mathrm{~K} \pm 15 \mathrm{~K}$ $\left(775{ }^{\circ} \mathrm{C} \pm 15^{\circ} \mathrm{C}\right)$ after the final roll pass and were air-cooled to room temperature. Hot band tensile properties were used to estimate the maximum cold work reductions possible prior to batch annealing. Steels were cold rolled using a Stanat TA 315 in a 4-high roll configuration to a reduction that equated to 2 to 3 times the elongation to failure of the hot-band materials. After cold rolling, the samples were placed in stainless steel bags containing gray iron machining chips and heated to $873 \mathrm{~K}\left(600{ }^{\circ} \mathrm{C}\right)$ at an average rate of $15 \mathrm{~K} / \mathrm{min}$, allowed to equilibrate, held for 20 hours, and cooled to $298 \mathrm{~K}$ $\left(25^{\circ} \mathrm{C}\right)$ at an average rate of $4 \mathrm{~K} / \mathrm{min}$, and approximates a heating and cooling cycle for a commercial batch anneal. 
Table I. Composition, Calculated Stacking Fault Energy, and Calculated Start Temperatures for $\varepsilon$ and $\alpha$ Martensites

\begin{tabular}{|c|c|c|c|c|c|c|c|c|c|}
\hline \multirow[b]{2}{*}{ Alloy } & \multicolumn{6}{|c|}{ Composition (Wt Pct) } & \multicolumn{3}{|c|}{ Calculated Parameters* } \\
\hline & $\mathrm{Mn}$ & $\mathrm{Si}$ & $\mathrm{Al}$ & $\mathrm{Cr}$ & $\mathrm{C}$ & $\mathrm{N}$ & $\operatorname{SFE}\left(\mathrm{mJ} / \mathrm{m}^{2}\right)$ & $\mathrm{Ms}^{\varepsilon} \mathrm{K}\left({ }^{\circ} \mathrm{C}\right)$ & $\mathrm{Ms}^{\alpha} \mathrm{K}\left({ }^{\circ} \mathrm{C}\right)$ \\
\hline $14 \mathrm{Mn}$ & 13.8 & 2.01 & 0.40 & - & 0.10 & 0.028 & -2.1 & 405 (132) & $381(108)$ \\
\hline $12 \mathrm{Mn}$ & 11.9 & 1.2 & - & 4.6 & 0.17 & 0.042 & 0.7 & $365(92)$ & 475 (202) \\
\hline $10 \mathrm{Mn}$ & 10.2 & 2.38 & 0.30 & - & 0.17 & 0.024 & -0.2 & 387 (114) & 417 (144) \\
\hline
\end{tabular}

*Calculated values assumed a homogeneous, single-phase austenite.

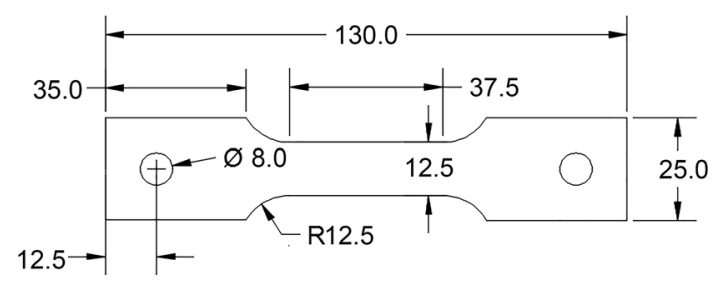

Fig. 3- Sample geometry of the DSA tensile bars with dimensions shown in millimeters.

Tensile tests were performed in accordance with ASTM E8 using standard tensile bars having a gage length of $50 \mathrm{~mm}$ and gage width of $12.5 \mathrm{~mm}$. All test specimens were mill-cut parallel to the rolling direction from both the hot-band and batch-annealed materials. ${ }^{[4]}$ Interrupted tensile tests were conducted at room temperature in displacement control at a rate of 0.01 $\mathrm{mm} / \mathrm{sec}$ using a $245 \mathrm{kN}$ servo-hydraulic test frame. Strain was continuously measured to failure using a non-contact laser extensometer. A non-standard tensile bar was used for the DSA studies as shown in Figure 3 with dimensions in $\mathrm{mm}$ and tensile axis parallel to the rolling direction. Test samples were cut by electro-discharge machining from the batch-annealed material. Activation energies for dynamic strain aging were determined by performing tensile tests at different strain rates $(\dot{\varepsilon})$ ranging from $10^{-4}$ to $10^{-2} \mathrm{~s}^{-1}$ using a $95 \mathrm{kN}$ servo-hydraulic test frame equipped with a temperature controlled environmental chamber with test temperatures ranging from $248 \mathrm{~K}$ to $673 \mathrm{~K}(-25$ ${ }^{\circ} \mathrm{C}$ to $400{ }^{\circ} \mathrm{C}$ ). Specimen strain was measured visually through a glass window in the environmental cell using the non-contact laser extensometer. Heating and cooling of the samples were performed at a constant $20 \mathrm{~K} / \mathrm{s}$ to the target temperature and the sample was held at temperature for 10 minutes to equilibrate prior to testing. Tests were performed in displacement control to obtain the desired strain rate, and the actual strain rate was calculated from the laser extensometer displacement data.

X-ray diffraction (XRD) specimens were obtained from interrupted tensile tests for both hot-band and batch-annealed conditions at varying degrees of strain to investigate the TRIP character of the material. XRD specimens were mechanically polished to $0.1 \mu \mathrm{m}$ using diamond paste in the Longitudinal-Transverse plane, (polished surface parallel to the rolling plane). Diffraction patterns were obtained using a Phillips X-pert diffractometer using a $\mathrm{Ni}$ filtered $\mathrm{Cu} \mathrm{K} \alpha$ radiation source and equipped with a flat graphite monochromator. Phase quantifications, including $\varepsilon$-martensite, were calculated utilizing the Rietveld refinement method described by Martin et al. ${ }^{[46]}$ for an Fe-16Cr-6.8Mn-6.1Ni steel, but modified accordingly for the steel chemistries investigated in this study. Polished samples $(1.0 \mathrm{~mm}$ in thickness) were mounted on to a platinum heating strip and elevated temperature XRD scans were performed by heating at a rate of $20 \mathrm{~K} / \mathrm{s}$ to the target test temperature. Once the target temperature was obtained, samples were held at temperature for 10 minutes to equilibrate and scanned from 30 to $90 \mathrm{deg}$. Argon cover gas was used to prevent oxidation of the samples.

Final polishing of EBSD samples was performed with a $0.02 \mu \mathrm{m}$ colloidal silica solution using a vibratory polisher and examined in the Longitudinal-Short plane (perpendicular to both the rolling plane normal and the rolling direction). Orientation image mapping via pattern analysis was performed using a Helios NanoLab 600 equipped with a Nordlys detector and the AZTEC software package. The electron beam was operated at an accelerating voltage of $20.0 \mathrm{kV}$ and emission currents of 5.5 to $11 \mathrm{nA}$. Electron dispersive spectrometry (EDS) mapping was conducted simultaneously to the EBSD mapping using a lithium drifted silicon detector with the same working parameters for the EBSD mapping. Orientation image maps and diffraction patterns were tilt corrected.

\section{RESULTS}

\section{A. Microstructure}

EBSD-OIM and EDS mapping were used to determine qualitatively the microstructural features of the as-processed and partially strained alloys. Hot band EBSD images are shown in Figure 4. All three hot band microstructures were composed of $\gamma$-austenite, $\varepsilon$-martensite, and $\alpha$-martensite. The microstructure of the $10 \mathrm{Mn}$ steel after batch annealing is shown in Figure 5. An average grain size of $0.34 \pm 0.01$ (95 pct CL) $\mu \mathrm{m}$ was measured using the band contrast map shown in Figure 5(a). Phase identification is shown in Figure 5(b) and a primarily $\alpha$-ferrite microstructure was produced by batch annealing with a minor fraction of $\gamma$-austenite containing some $\varepsilon$-martensite.

Less $\alpha$-ferrite was produced during batch-annealing of the 14-Mn alloy as shown in Figure 6. The grain size was also bimodal with alloy-rich regions being fully austenitic (average grain diameter of $3.0 \pm 0.3 \mu \mathrm{m}$ ) and 

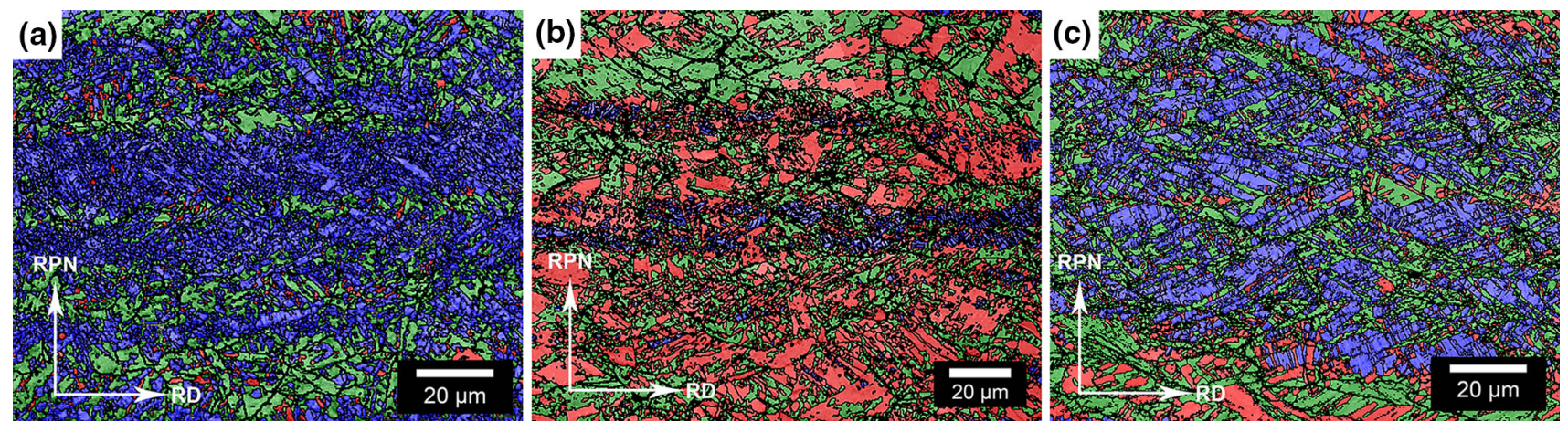

Fig. 4-EBSD-OIM images of the unstrained hot band $(a) 10 \mathrm{Mn},(b) 12 \mathrm{Mn}$, and $(c) 14 \mathrm{Mn}$ alloys. Where $\gamma$-austenite is shown as green, $\varepsilon$-martensite is red, and $\alpha$-ferrite is blue (Color figure online).
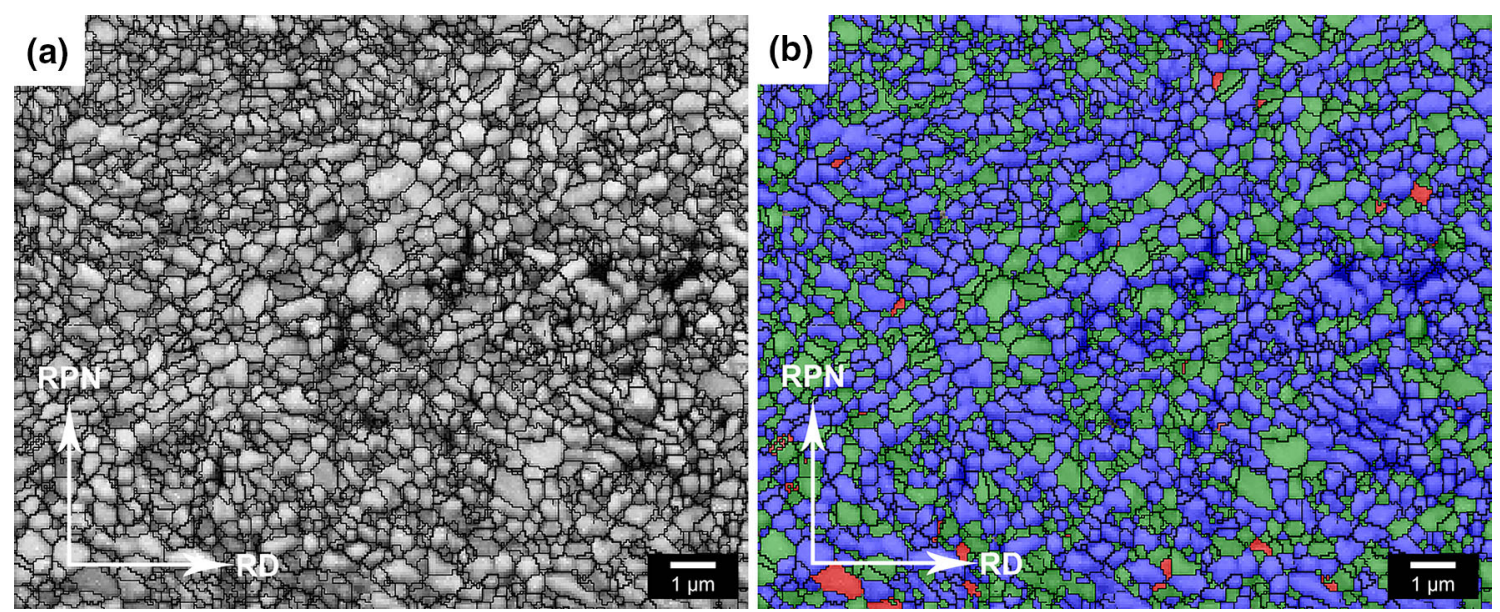

Fig. 5- (a) Band contrast map of the batch annealed 10Mn steel, and (b) Phase map of the unstrained 10Mn alloy after batch annealing where $\gamma$-austenite (green) $\varepsilon$-martensite (red) and $\alpha$-ferrite (blue) (Color figure online).
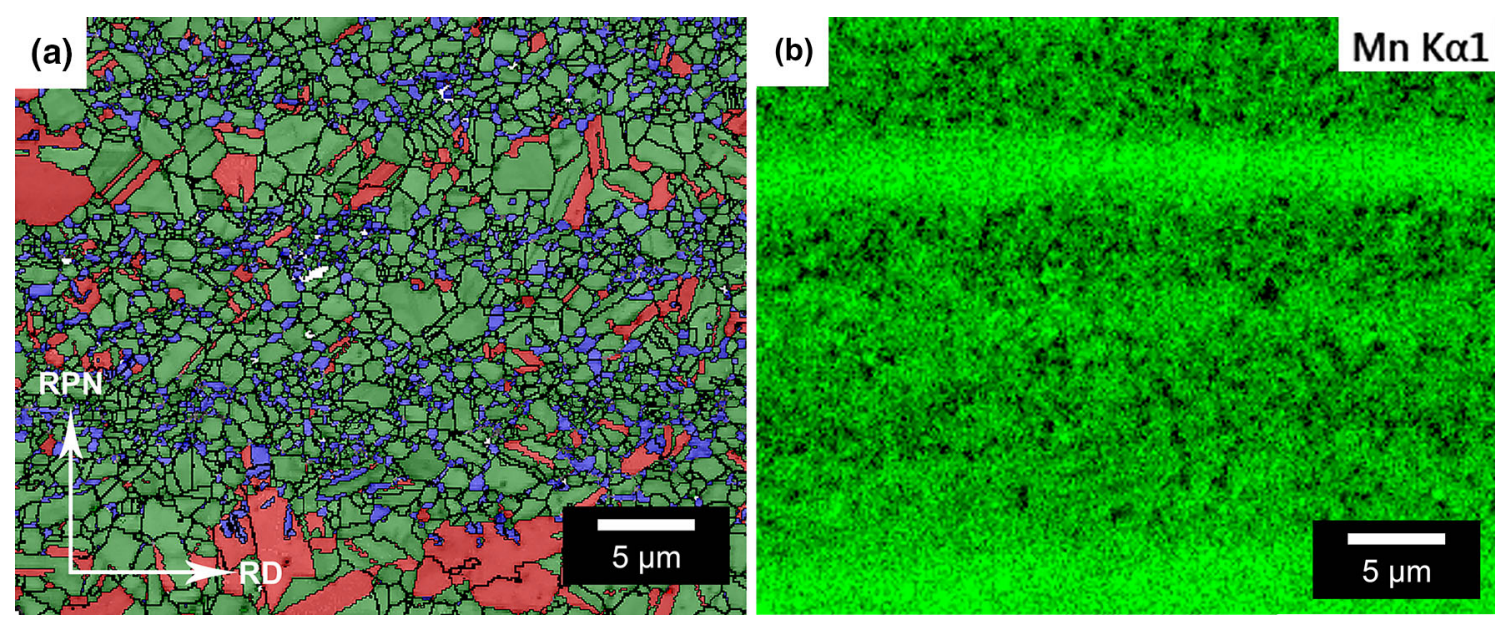

Fig. 6- (a) EBSD-OIM map of the cold worked and annealed 14Mn alloy which depicts the equiaxed $\gamma$-austenite (green) $\varepsilon$-martensite (red) and $\alpha$-ferrite/martensite (blue), and (b) compositional map of manganese concentration (Color figure online).

alloy lean regions being a mixture of $\alpha$-ferrite and $\gamma$-austenite with an average grain diameter of $1.1 \pm 0.4$ $\mu \mathrm{m}$. The effect of banding in the microstructure on the mechanical response of the steel is not well understood, and will be a topic of further investigation in future works. Both athermal $\varepsilon$-martensite and $\alpha$-martensite are observed in the $\gamma$-austenite of the $14 \mathrm{Mn}$ alloy see Figure 6(a). Athermal $\alpha$-martensite was differentiated from $\alpha$-ferrite by noting that the $\alpha$-ferrite formed during batch annealing was equiaxed and depleted in $\mathrm{Mn}$ as 

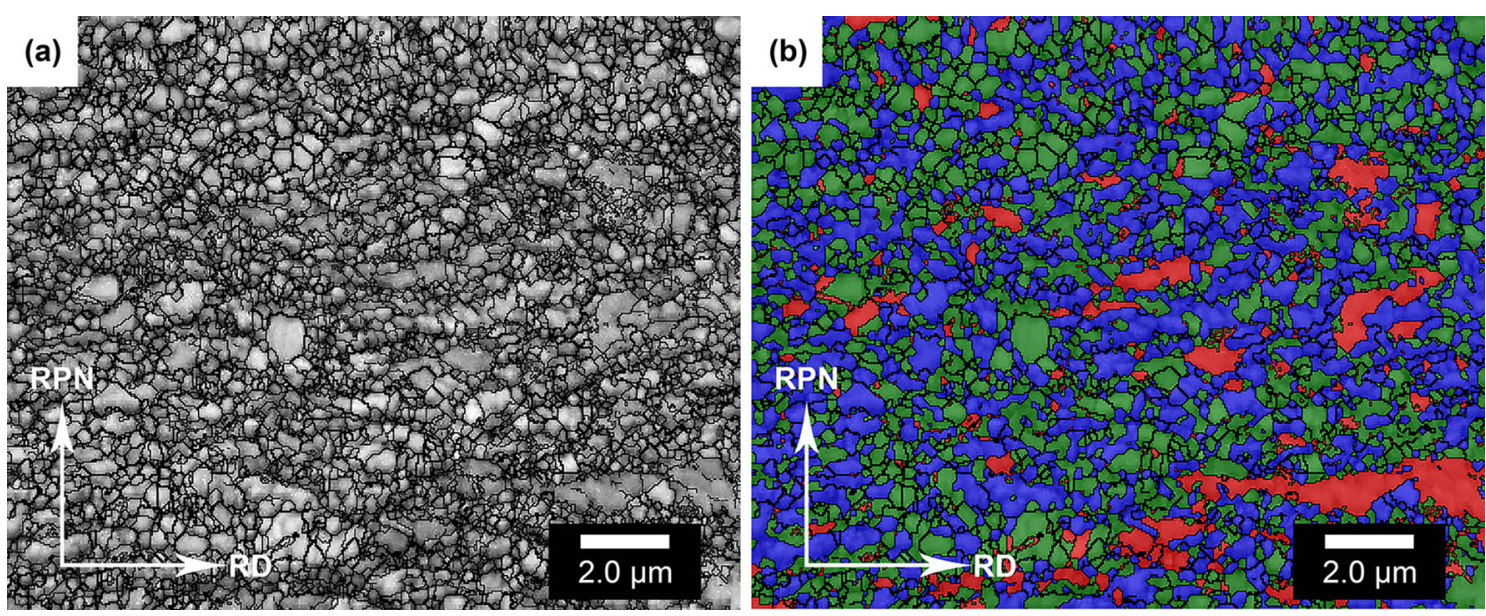

Fig. 7- (a) Band contrast map of the batch annealed 12Mn steel, and (b) Phase map of the unstrained 12Mn alloy after batch annealing where $\gamma$-austenite (green), $\varepsilon$-martensite (red), and $\alpha$-ferrite (blue) (Color figure online).

Table II. Volume Percent of Phases for the Three Alloys Investigated in the Hot Band, and Cold Worked and Annealed Conditions Values Obtained According to XRD

\begin{tabular}{|c|c|c|c|c|c|c|}
\hline \multirow[b]{2}{*}{ Alloy } & \multicolumn{3}{|c|}{ Hot Band } & \multicolumn{3}{|c|}{ Cold Worked and Annealed } \\
\hline & $\gamma$ & $\varepsilon$ & $\alpha$ & $\gamma$ & $\varepsilon$ & $\alpha$ \\
\hline $14 \mathrm{Mn}$ & 14 & 45 & 41 & 67 & 14 & 19 \\
\hline $12 \mathrm{Mn}$ & 23 & 51 & 26 & 37 & 33 & 30 \\
\hline $10 \mathrm{Mn}$ & 20 & 26 & 54 & 32 & 10 & 58 \\
\hline
\end{tabular}

Table III. Composition of the Phases of Interest in Wt Pct Using EDS and a 95 Pct CL Standard Deviation. FactSage Calculated Values are Also Shown for Comparison

\begin{tabular}{|c|c|c|c|c|c|c|c|c|c|c|c|}
\hline & & \multicolumn{5}{|c|}{$\gamma$-Austenite } & \multicolumn{5}{|c|}{$\alpha$-Ferrite } \\
\hline & & $\mathrm{C}$ & $\mathrm{N}$ & $\mathrm{Mn}$ & $\mathrm{Ms}^{\varepsilon} \mathrm{K}\left({ }^{\circ} \mathrm{C}\right)$ & $\mathrm{Ms}^{\alpha} \mathrm{K}\left({ }^{\circ} \mathrm{C}\right)$ & $\mathrm{C}$ & $\mathrm{Mn}$ & $\mathrm{Cr}$ & $\mathrm{Al}$ & $\mathrm{N}$ \\
\hline \multirow[t]{2}{*}{$10 \mathrm{Mn}$} & EDS & $0.36^{*}$ & $0.081 *$ & $12.3 \pm 3.0$ & $340(67)$ & $421(148)$ & $0.02 *$ & $9.01 \pm 3.31$ & - & $0.3 \pm 0.2$ & $0.1^{*}$ \\
\hline & FactSage & 0.38 & 0.058 & 18.6 & & & $<0.0001$ & 3.82 & - & 0.51 & $<0.001$ \\
\hline \multirow[t]{2}{*}{$12 \mathrm{Mn}$} & EDS & $0.006^{*}$ & $0.004^{*}$ & $14.6 \pm 2.5$ & 404 (131) & 439 (166) & $0.02 *$ & $11.5 \pm 3.0$ & $3.8 \pm 0.8$ & - & $0.1^{*}$ \\
\hline & FactSage & 0.007 & 0.001 & 15.1 & & & $<0.0001$ & 3.92 & 2.16 & - & $<0.001$ \\
\hline \multirow[t]{2}{*}{$14 \mathrm{Mn}$} & EDS & $0.11 *$ & $0.011 *$ & $15.9 \pm 3.1$ & 376 (103) & - & $0.02 *$ & $10.9 \pm 3.8$ & - & $0.4 \pm 0.1$ & $0.1^{*}$ \\
\hline & FactSage & 0.12 & 0.054 & 17.3 & & & $<0.0001$ & 4.1 & - & 0.52 & $<0.001$ \\
\hline
\end{tabular}

*Values of carbon and nitrogen reported were calculated assuming full partitioning.

revealed by the complimentary elemental mapping of Mn shown in Figure 6(b). When present, the athermal $\alpha$-martensite was contained in bands of $\varepsilon$-martensite.

The grain structure of the chromium modified $12 \mathrm{Mn}$ alloy is similar to the $10 \mathrm{Mn}$ alloy and an average grain size of $0.67 \pm 0.02 \mu \mathrm{m}$ was measured from the band contrast map shown in Figure 7(a); phase identification by EBSD of $\alpha$-ferrite, $\gamma$-austenite and athermal $\varepsilon$-martensite is shown in Figure $7(\mathrm{~b})$. Phase fractions as determined using XRD for the hot band and the batch annealed steels are shown in Table II. From the phase fractions of the $\alpha$-ferrite measured using XRD and the measured Mn content according to the EDS analysis, a composition of the $\gamma$-austenite and $\alpha$-ferrite is shown in Table III; concentrations of $\mathrm{C}$ and $\mathrm{N}$ are calculated assuming complete partitioning; however, equilibrium may not have been reached. As a result, the extensive partitioning to $\gamma$-austenite of carbon and nitrogen may not be fully attained since non-equilibrium distribution of the substitutional alloys will affect the activity of both carbon and nitrogen distributions. The Ms temperatures of the $\gamma$-austenite are recalculated according to the measured EDS data; however, the manganese content of the $14 \mathrm{Mn}$ alloy $\gamma$-austenite is outside of the range for the $\mathrm{Ms}^{\alpha}$ model derived by Field et al. ${ }^{[42]}$ For the Cr-modified $12 \mathrm{Mn}$ alloy an equilibrium amount of $2.8 \mathrm{wt}$ pet $\mathrm{M}_{23}(\mathrm{C}, \mathrm{N})_{6}$ is assumed to be present in the microstructure and its effect on denuding the $\gamma$-austenite of $\mathrm{C}$ is shown in Table III. FactSage was also utilized to compare the software prediction to the measured composition of the phases. It should be noted that the measured $\mathrm{Mn}$ content of the $\alpha$-ferrite is higher 


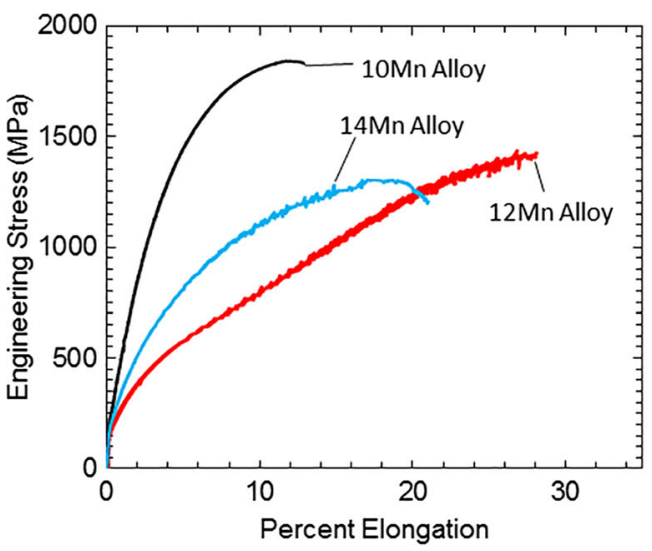

(a)

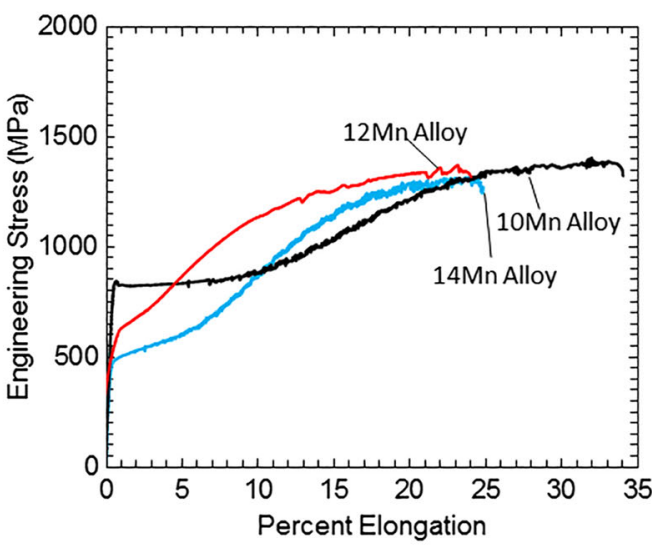

(b)

Fig. 8- Stress-strain graph of the $(a)$ hot band and $(b)$ batch annealed steels.

Table IV. Mechanical Properties of the Hot Band and Processed Steel, Tested at Room Temperature $\left(298 \mathrm{~K}, 25^{\circ} \mathrm{C}\right)$

\begin{tabular}{|c|c|c|c|c|c|c|c|c|c|c|c|}
\hline \multirow[b]{2}{*}{ Alloy } & \multicolumn{5}{|c|}{ Hot Band } & \multirow[b]{2}{*}{ Cold Work (Pct) } & \multicolumn{5}{|c|}{ Cold Worked and Annealed } \\
\hline & YS $(\mathrm{MPa})$ & UTS (MPa) & $e_{\mathrm{f}}(\mathrm{Pct})$ & $\mathrm{K}(\mathrm{MPa})$ & $n$ & & YS (MPa) & UTS (MPa) & $e_{\mathrm{f}}(\mathrm{Pct})$ & $\mathrm{K}(\mathrm{MPa})$ & $n$ \\
\hline $14 \mathrm{Mn}$ & 240 & 1304 & 21.0 & 4220 & 0.51 & 53.6 & 500 & 1316 & 24.8 & 6810 & 0.81 \\
\hline $12 \mathrm{Mn}$ & 190 & 1436 & 28.1 & 5700 & 0.78 & 55.1 & 650 & 1310 & 25.0 & 3370 & 0.33 \\
\hline $10 \mathrm{Mn}$ & 260 & 1841 & 12.9 & 8750 & 0.59 & 35.6 & 837 & 1404 & 34.1 & 4920 & 0.70 \\
\hline
\end{tabular}

for all alloys compared to FactSage's predicted composition of $\sim 4 \mathrm{wt}$ pct $\mathrm{Mn}$, and this leads to the lower measured $\mathrm{Mn}$ content in the $\gamma$-austenite grains compared to the calculated amount of $\mathrm{Mn}$ in the $\gamma$-austenite composition.

\section{B. Tensile Behavior}

Stress-strain plots of hot-band and batch-annealed steels are shown in Figures 8(a) and (b), with a summary of the tensile properties given in Table IV. All three alloys in the hot-band condition show a continuous work hardening behavior with no evidence of yield point elongation. Post necking plastic strain was observed in the $10 \mathrm{Mn}$ and $14 \mathrm{Mn}$ alloys, whereas the $12 \mathrm{Mn}$ alloy failed prior to the onset of necking. Serrated flow indicating dynamic strain aging was observed in the hot-band stress-strain data of the $12 \mathrm{Mn}$ and $14 \mathrm{Mn}$ alloys. Yield point and yield point elongation were observed after cold working and batch annealing; both the $10 \mathrm{Mn}$ and $14 \mathrm{Mn}$ alloys exhibit Type B serrations, whereas the $\mathrm{Cr}$ bearing $12 \mathrm{Mn}$ alloy has a reduced occurrence of DSA and appears to exhibit Type A/E serrations that occur at higher strain levels. If the yield point elongation is subtracted from the $10 \mathrm{Mn}$ alloy, the failure strain for all three alloys is approximately $25 \mathrm{pct}$ in the batch-annealed condition.

Interrupted tensile tests followed by quantitative XRD were performed on both the hot band and the batch annealed steels to determine the TRIP behavior of the steels. Volume fraction of the three crystal structures ( $\gamma$-austenite, $\varepsilon$-martensite, and $\alpha$-martensite/ferrite) as a function of total strain is shown in Figures 9(a) through (f) for the three alloys in both hot-band and batch-annealed conditions. The only hot-band alloy that exhibits the two-stage TRIP behavior is the 14Mn steel and the behavior is similar to that reported by McGrath et al. ${ }^{[13]}$ where $\gamma$-austenite first transforms to $\varepsilon$-martensite until saturation and subsequently to $\alpha$-martensite. In contrast, an initial $\varepsilon \rightarrow \alpha$ transformation is observed in the hot band $10 \mathrm{Mn}$ alloy, see Figure 9(a), and once the athermal $\varepsilon$-martensite is consumed the $\gamma$-austenite transforms to $\varepsilon$-martensite. This phenomenon in transformation response is considered to be a material property and not a sample variation artifact. This is demonstrated by overlaying the stress-strain curve of each specimen tested to varying total strains as shown in Figure 10, where each unloading curve is a separate specimen that was used to quantify the strained microstructure using XRD.

After cold working and annealing, all three steels exhibit a similar two-stage TRIP response with $\gamma$-austenite first transforming to $\varepsilon$-martensite and $\varepsilon$-martensite transforming subsequently to $\alpha$-martensite. It is shown in Figure 11(a) of the 12 pct strained $14 \mathrm{Mn}$ alloy that the $\alpha$-martensite which forms is confined to prior $\varepsilon$-martensite bands. The Stage $\mathrm{I} \rightarrow \mathrm{II}$ transition strain was consistent for all three alloys up to approximately 5 pet strain. Figure 11(b) shows orientation image map of the $\alpha$-phase, and the adjacent $\alpha$-martensite plates that 


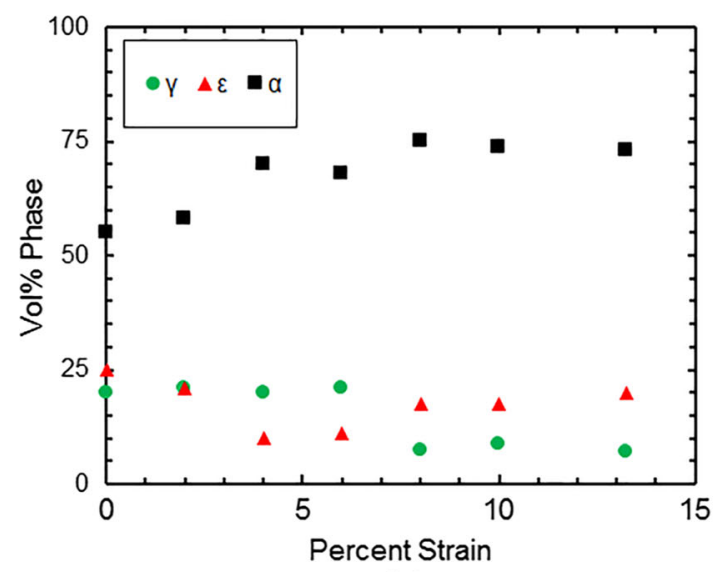

(a)

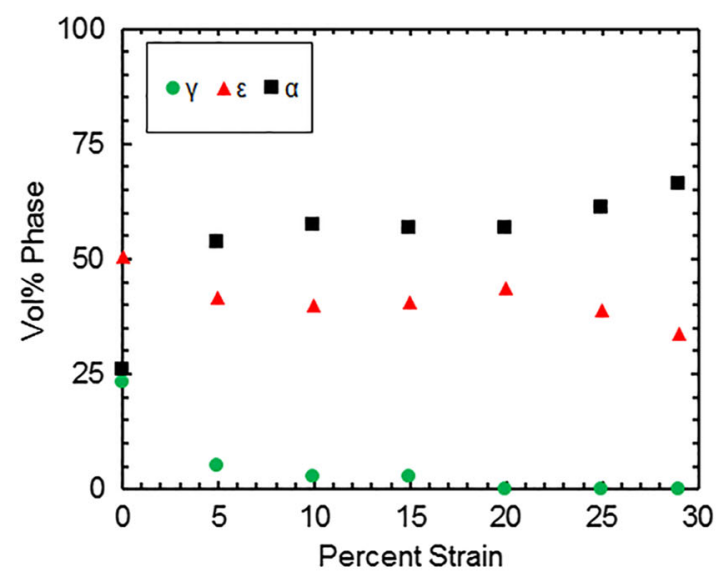

(c)

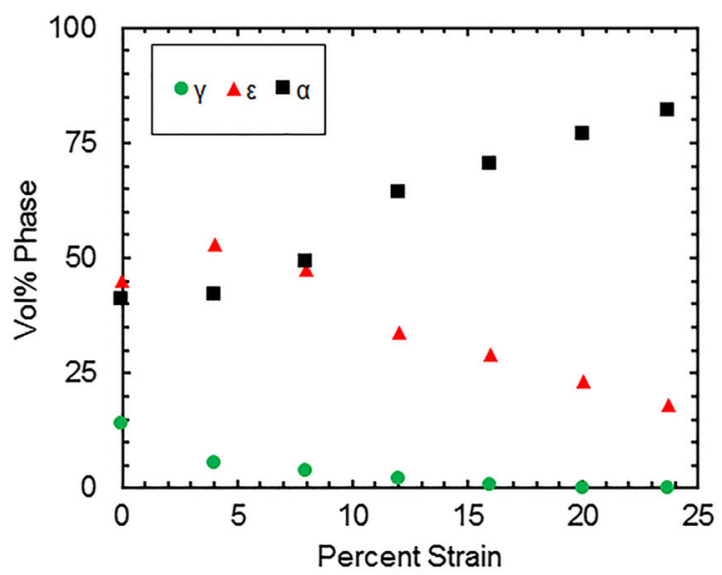

(e)

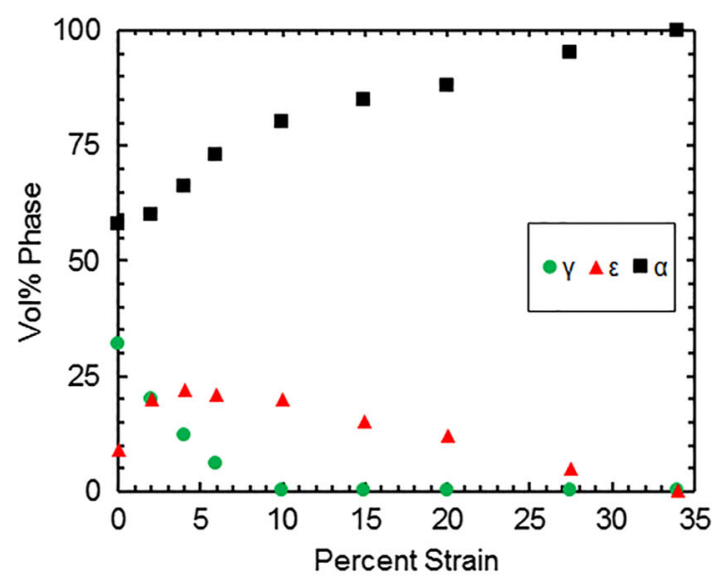

(b)

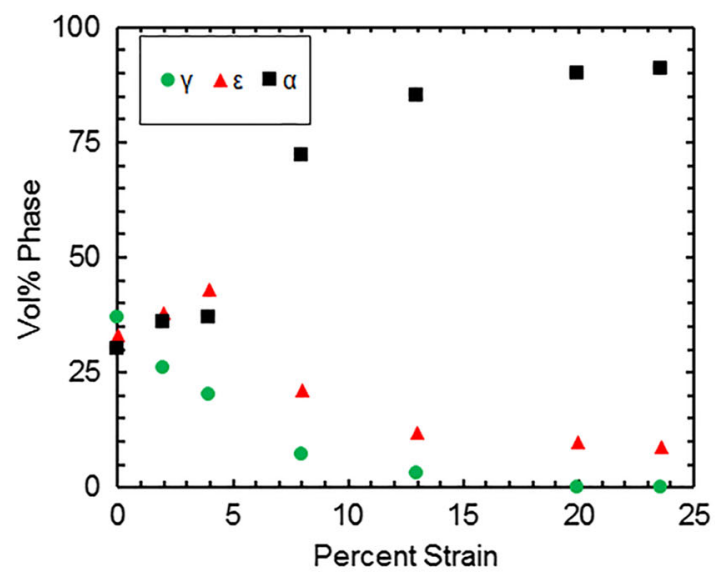

(d)

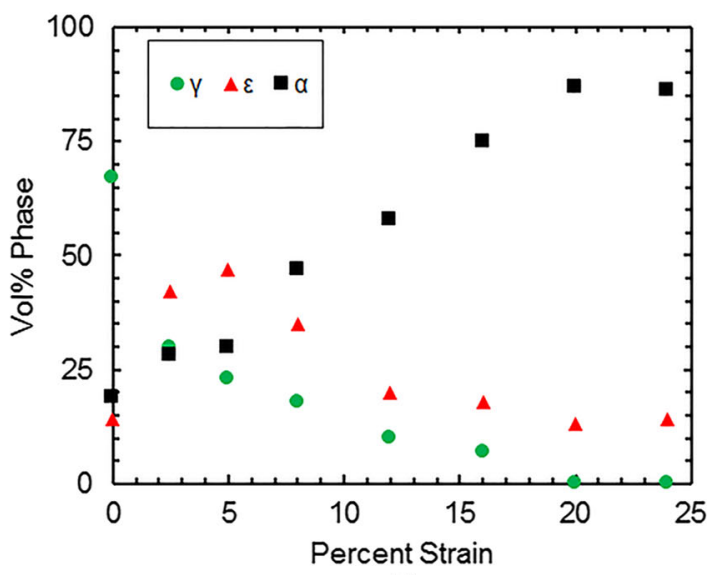

(f)

Fig. 9-Volume percent of the phases as a function of strain. For the 10Mn alloy in the $(a)$ hot band and $(b)$ annealed conditions. The chromium modified 12Mn alloy in the $(c)$ hot band and $(d)$ annealed condition, and the 14Mn alloy in the $(e)$ hot band and $(f)$ annealed condition.

formed during Stage II transformation and the $\alpha$-martensite plates appear to be twin related according to their orientation (highlighted with arrows in Figure 11(b)) as has been shown by Pisarik and Van Aken for athermal transformations ${ }^{[47]}$ as well as Kinney et $a{ }^{[48]}$ for the athermal reaction.

\section{Dynamic Strain Aging and Activation Energy}

Activation energies for the onset and termination of DSA were determined using tensile tests performed at varying strain rates $(\dot{\varepsilon})$ and temperatures $(T)$. Dynamic strain aging was characterized for the serrations that occurred during the Stage II $(\varepsilon \rightarrow \alpha)$ tensile response. This 
is best exemplified in Figure 12 comparing two samples of $10 \mathrm{Mn}$ tested at strain rates of $10^{-2}$ and $10^{-4} \mathrm{~s}^{-1}$, at $573 \mathrm{~K}\left(300^{\circ} \mathrm{C}\right)$. Two work hardening rates are observed for the specimens tested at a $10^{-4} \mathrm{~s}^{-1}$, with the initial portion of the stress-strain curve exhibiting Lüders-like strain; however, unlike Lüders strain or yield point elongation observed in plain carbon steels, the results in Figure 12 show strain hardening. Once these Lüders type serrations are exhausted, a secondary work hardening rate with no DSA occurs with a strain rate of $10^{-4}$ $\mathrm{s}^{-1}$ at $573 \mathrm{~K}\left(300{ }^{\circ} \mathrm{C}\right)$ and this test result is classified as a non-DSA sample for this analysis. Figure 12(b) shows a magnified portion of the Stage II work hardening with and without DSA. Noise in the non-DSA work hardening curve $\left(10^{-4} \mathrm{~s}^{-1}\right.$ at $\left.573 \mathrm{~K}\right)$ is typical baseline for the laser extensometer. This classification methodology was carried out for all test temperatures and strain rates. Activation energies were determined from graphs of the $\ln (\dot{\varepsilon})$ vs. $1000 / \mathrm{T}$ (with temperature in Kelvin) noting when DSA occurred. A dynamic strain aging map is shown for the 10Mn steel in Figure 13(a) with an activation energy for DSA initiation measured to be 64

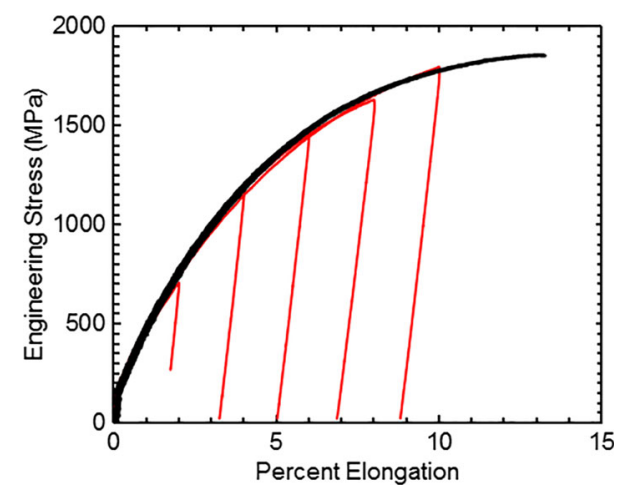

Fig. 10- Stress-strain curves of the 10Mn hot band alloy for the six samples tested to varying total strains used to determine the transformation response as a function of strain.

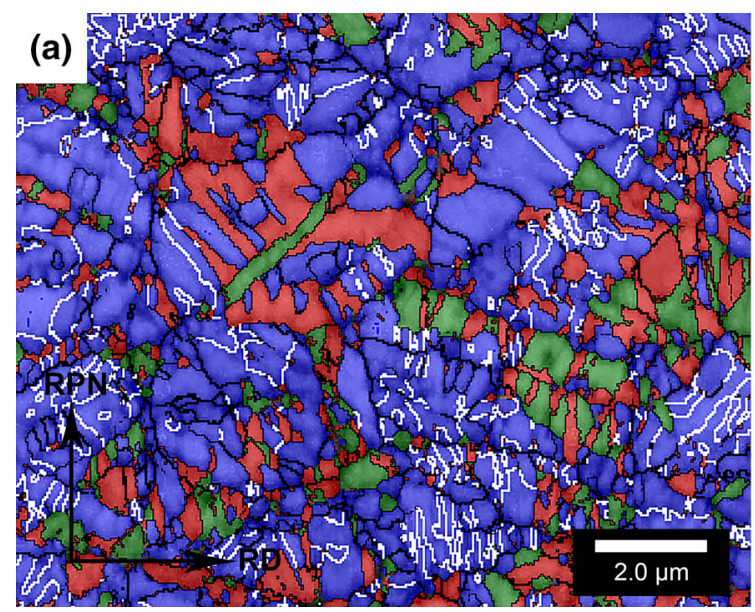

$\pm 6 \mathrm{~kJ} / \mathrm{mol}$, and the activation energy for DSA termination is $123 \pm 12 \mathrm{~kJ} / \mathrm{mol}$. From the DSA map of the Cr-modified 12Mn alloy in Figure 13(b) the onset of DSA is measured as $145 \pm 15 \mathrm{~kJ} / \mathrm{mol}$, and termination energy is $277 \pm 8 \mathrm{~kJ} / \mathrm{mol}$. From Figure 13(c) the $14 \mathrm{Mn}$ steel; activation energy for DSA initiation is $88 \pm$ $15 \mathrm{~kJ} / \mathrm{mol}$ and the termination energy for the $14 \mathrm{Mn}$ alloy is measured to be $155 \pm 5 \mathrm{~kJ} / \mathrm{mol}$.

XRD phase fractions at elevated temperatures of the processed steels are shown in Figures 14(a) through (c). The authors however wish to stress that the transformation response upon straining is only known for room temperature samples. DSA transition regions are highlighted with gray bands for both the low temperature initiation and elevated temperature termination. Phase quantifications for tensile tests above ambient temperature $(>298 \mathrm{~K}$ ) were performed using a heating stage equipped diffractometer. A cooling stage was not available for phase identification at lower temperatures. It is noted that for the $10 \mathrm{Mn}$ alloy the termination zone of DSA is observed to occur when the $\gamma$-austenite and $\alpha$-ferrite become an even distribution of phases. The Cr-modified $12 \mathrm{Mn}$ steel contains the greatest volume fraction of $\varepsilon$-martensite in the starting structure and is observed that there is little change to the microstructural constituents for both the initiation and termination regions of the DSA response. The $14 \mathrm{Mn}$ alloy contains the greatest volume fraction of $\gamma$-austenite and the termination of serrations does not occur until $\varepsilon$-martensite reversion occurs.

To confirm the efficacy of the annealing cycle and the precipitation of the carbo-nitride, a $12 \mathrm{Mn}$ sample was re-austenitized at $1123 \mathrm{~K}\left(850{ }^{\circ} \mathrm{C}\right)$ within a single-phase field according to the results presented in Figure 2. The specimen was held at temperature for 1 hour to fully dissolve the carbo-nitrides and quenched to room temperature. Room temperature tensile tests at a strain rate of $10^{-4} \mathrm{~s}^{-1}$ produce DSA. A comparison of the XRD scans for both the batch annealed and austenitized and water quenched samples are shown in Figure 16. A carbide peak is observed for the $(020)$, labeled as $\underline{\mathrm{C}}$ in

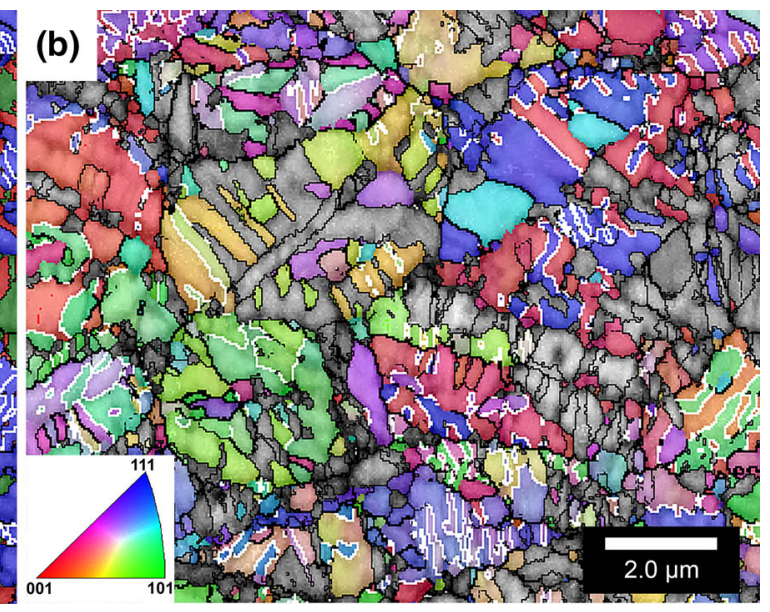

Fig. 11-(a) Phase map of the 12 pct strained 14Mn alloy $\gamma$-austenite (green), $\varepsilon$-martensite (red), and $\alpha$-ferrite/martensite (blue) and (b) the orientation image map of the bcc structure with the orientation relative to the rolling direction ( $x$-axis). White delineated phase boundaries are used to highlight twin related $\alpha$-martensite variants (Color figure online). 


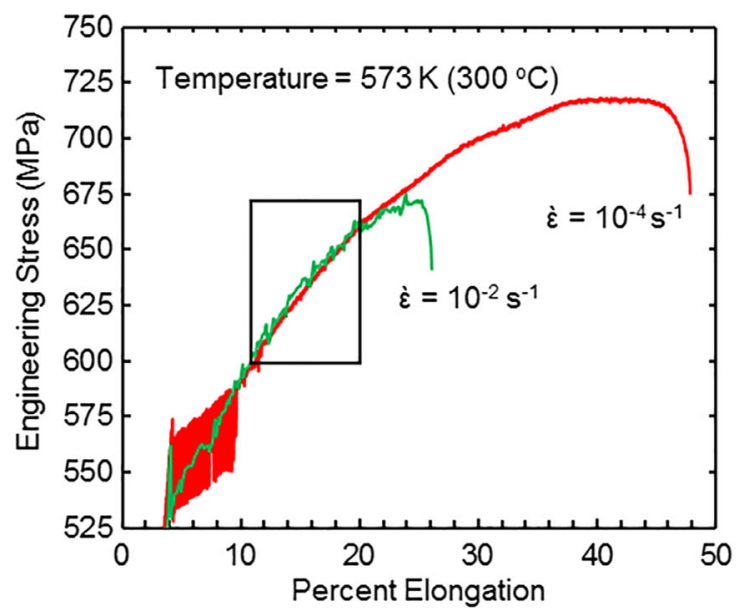

(a)

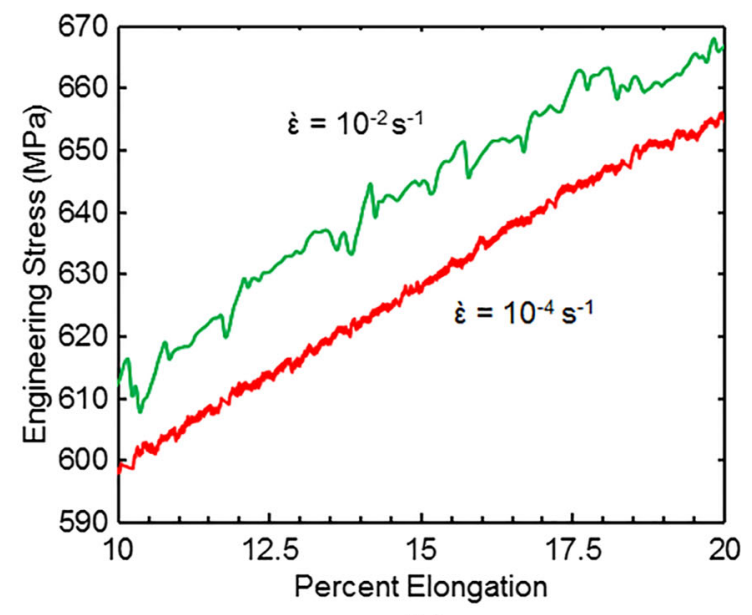

(b)

Fig. 12- (a) Comparison of the engineering stress-strain curve of the $10 \mathrm{Mn}$ alloy at $573 \mathrm{~K}\left(300{ }^{\circ} \mathrm{C}\right)(\mathrm{b})$ detailed view in the range of 12 to 20 pct strain illustrating the similarity in the work hardening rate within and outside the DSA region. The $\dot{\varepsilon}=10^{-2} \mathrm{~s}^{-1}$ exhibits DSA with a work hardening rate $1540 \mathrm{MPa}$ and strain hardening exponent of $n=0.35$. The $\dot{\varepsilon}=10^{-4} \mathrm{~s}^{-1}$ sample does not exhibit DSA and has a work hardening rate of $1505 \mathrm{MPa}$ and a strain hardening exponent of $n=0.33$

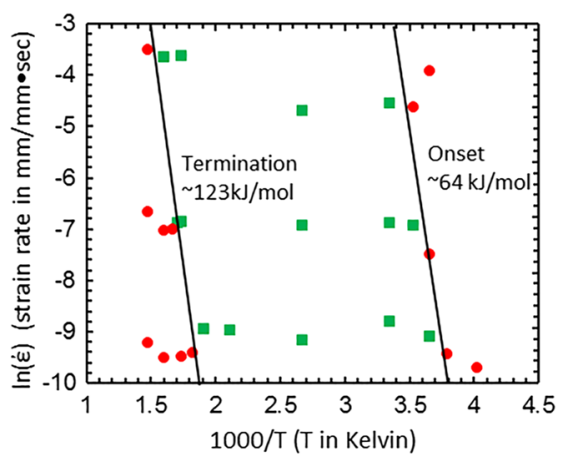

(a)

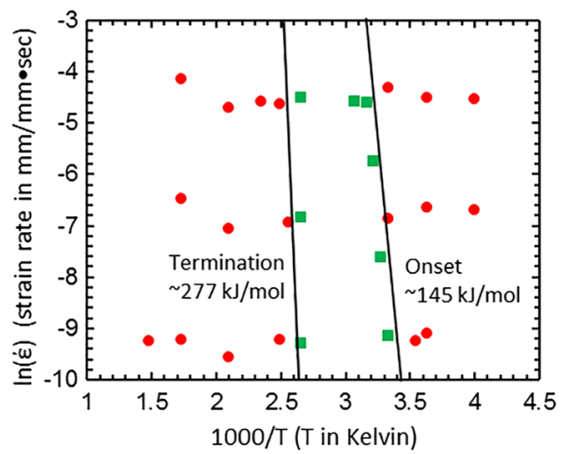

(b)

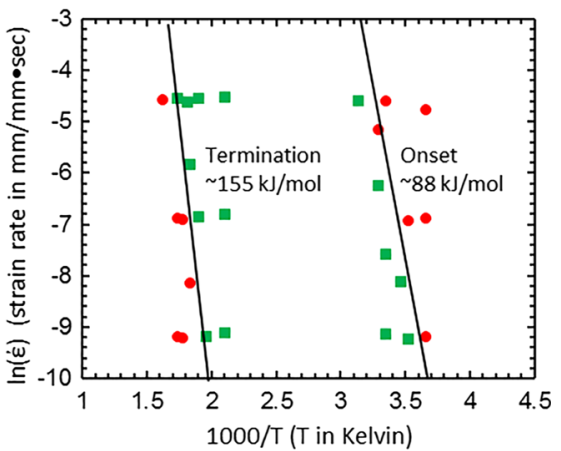

(c)

Fig. 13-DSA map of the (a) 10Mn alloy, (b) 12Mn alloy, and (c) 14Mn alloy. Circles denote samples which did not exhibit DSA during tensile testing and squares denote samples that did exhibit the typical serrated flow associated with DSA.

the XRD spectrum, only in the annealed sample. After austenitization and water quenching, the carbide peak is no longer observed.

\section{DISCUSSION}

Multiple dynamic strain aging mechanisms are possible as evidenced by the results obtained in this study where onset and termination activation energies for the three alloys studied vary from 64 to $145 \mathrm{~kJ} / \mathrm{mol}$ and 123 to $277 \mathrm{~kJ} / \mathrm{mol}$, respectively. Analysis of the onset and termination energies is also complicated by the fact that in two of the alloys (10Mn and $14 \mathrm{Mn}$ ) the relative portions of the various phases change in the DSA active test range of temperature and strain rate. There is also the possibility that two or more DSA mechanisms may overlap during either the onset or the termination. However, in two of the alloys (12Mn and $14 \mathrm{Mn}$ ) a clear case can be made to propose a single mechanism.
For the Cr-modified 12Mn alloy, it is observed that the onset of DSA occurs at higher temperatures for all strain rates compared to the $10 \mathrm{Mn}$ and $14 \mathrm{Mn}$ alloy. An activation energy for DSA of $145 \pm 14 \mathrm{~kJ} / \mathrm{mol}$ is reported in Figure 13(b). This value is greater than the activation energy of $134 \mathrm{~kJ} / \mathrm{mol}$ reported for carbon diffusion in $\gamma$-austenite. ${ }^{[49]}$ It might also be possible to discount any mechanism associated with either nitrogen or carbon interstitials based upon the calculated concentration of those elements in equilibrium with $\mathrm{M}_{23}(\mathrm{C}, \mathrm{N})_{6}$ as shown in Table III. Solubility of nitrogen and carbon in $\gamma$-austenite at the batch annealing temperature were 10 and $70 \mathrm{ppm}$, respectively. The effectiveness of the $\mathrm{M}_{23}(\mathrm{C}, \mathrm{N})_{6}$ in reducing the interstitial contribution was also demonstrated by heating the alloy above the solvus temperature of the carbo-nitride, quenching, and testing in the fully austenitic condition as shown in Figures 15 and 16.

The onset activation energy is also well above that measured for DSA by Venkadesan et al. ${ }^{[35]}$ in titanium-treated austenitic stainless steels where a 42 pct 


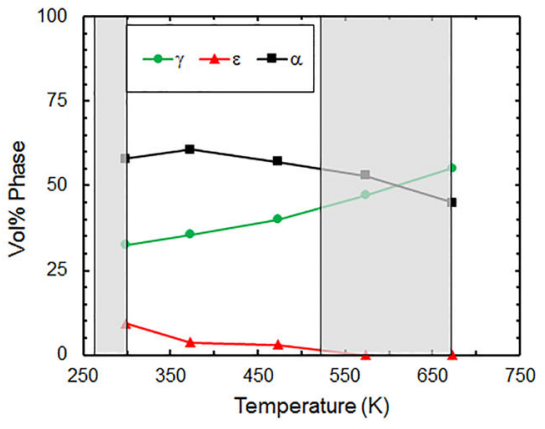

(a)

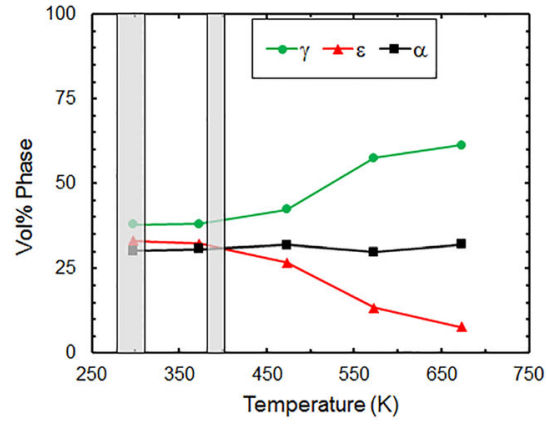

(b)

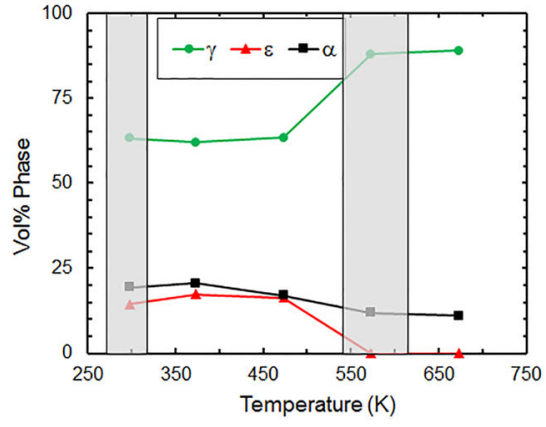

(c)

Fig. 14-Volume percent phase as a function of temperature for the (a) 10Mn, (b) 12Mn, and (c) 14Mn alloys. The DSA transition regions are highlighted within the gray bands.

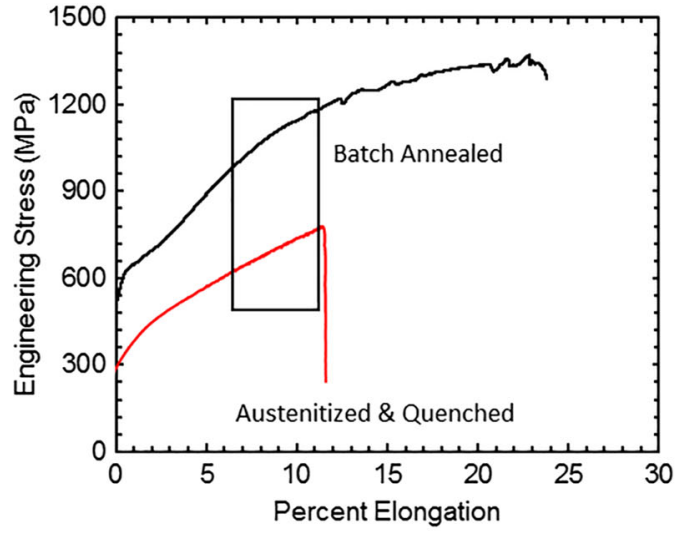

(a)

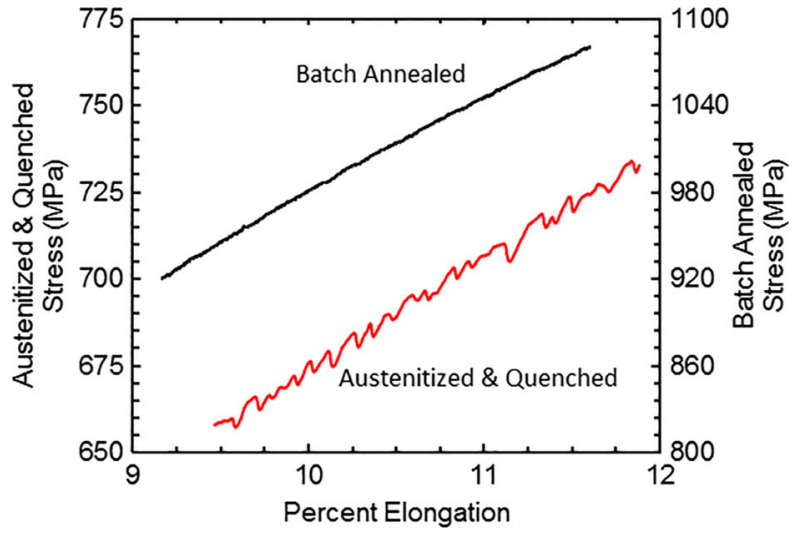

(b)

Fig. 15- (a) Stress-strain of the austenitized and quenched and the batch annealed 12Mn alloy, and $(b)$ detailed view of both tensile curved at strains of 9 to 12 pct, it should be noted the stress-axis is adjusted to magnify both tensile responses.

increase in the activation energy for the onset of DSA was measured for the steel containing a higher titanium content. The low titanium $(0.21 \mathrm{wt} \mathrm{pct})$ stainless steel had an activation energy of $85 \mathrm{~kJ} / \mathrm{mol}$ while the higher Ti steel $(0.32 \mathrm{wt}$ pct) had a measured activation energy of $121 \mathrm{~kJ} / \mathrm{mol}$. Both values are less than the activation energy for carbon diffusion in $\gamma$-austenite. In addition, Venkadesan et al. report no measured difference in the termination energy $(180 \pm 8 \mathrm{~kJ} / \mathrm{mol})$ for DSA despite an increase in titanium content. This would imply that the cause of the DSA was related to interstitials in solution, and the change in initiation energy is indicative of the reduced concentration of $\mathrm{C}$, and $\mathrm{N}$ resulting from $\mathrm{Ti}(\mathrm{C}, \mathrm{N})$ precipitation and shown mathematically in Eq. [1]. In a similar fashion, Choudhary et al. ${ }^{[34]}$ report the efficacy of an annealing treatment to a $9 \mathrm{Cr}-1 \mathrm{Mo}$ ferritic steel to precipitate and coarsen $\mathrm{Cr}$-carbides and nitrides. Choudhary et al. found that by coarsening the carbides and nitrides the magnitude of serrations was reduced and the critical strain for DSA was increased.

The termination energy of $277 \pm 8 \mathrm{~kJ} / \mathrm{mol}$ measured for the $12 \mathrm{Mn}$ alloy is well above that reported for DSA mechanisms associated with interstitials in $\gamma$-austenite. However, this activation energy is very close to the reported activation energy for lattice diffusion of $\mathrm{Mn}$ in

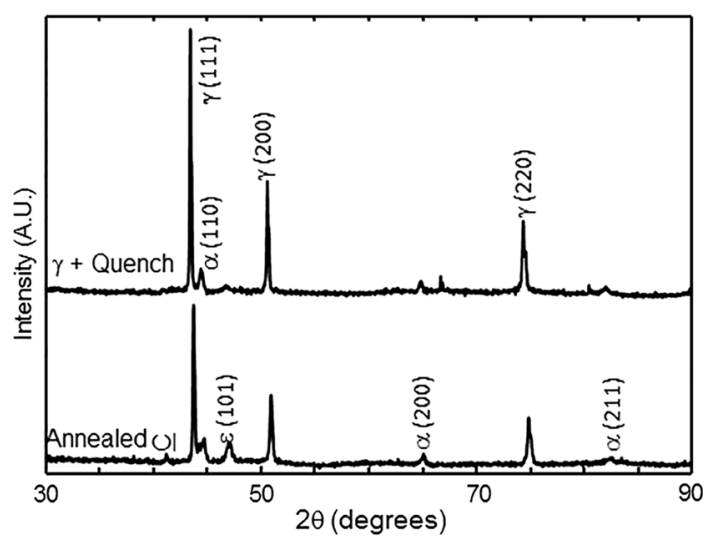

Fig. 16-XRD scans of the batch annealed and the austenitized and quenched samples. Peak locations are identified to the crystal structure and the carbide peak is labeled as $\underline{\mathrm{C}}$.

austenite $276 \mathrm{~kJ} / \mathrm{mol} .{ }^{[50]}$ As proposed by Balluffi ${ }^{[22]}$, the activation energy can range from 0.4 to 0.7 of bulk diffusion for pipe diffusion within a dislocation core and the onset activation energy of $145 \mathrm{~kJ} / \mathrm{mol}$ represents 0.52 of the lattice diffusion of $\mathrm{Mn}$ in $\gamma$-austenite. ${ }^{[22]}$ It should also be noted that $\varepsilon$-martensite is stable throughout the 
region of DSA and at temperatures above where the termination energy of DSA was measured. The $\varepsilon$-martensite phase can be thought of as a series of intrinsic stacking faults bounded by partial dislocations. Thus, one possible mechanism might include a defect complex with Mn associated with the austenite and the $\varepsilon$-martensite interface. Interestingly, Medvedeva et al. ${ }^{[25]}$ have shown that the ISF energy is lowered when Mn is situated at the fault plane. Work by Oi et al. ${ }^{[51]}$ showed that the binding energy for the Mn interphase boundary pair is $8 \mathrm{~kJ} / \mathrm{mol}$. This would imply that the theoretical termination energy for DSA in the Cr-modified $12 \mathrm{Mn}$ alloy should be $284 \mathrm{~kJ} / \mathrm{mol}$, and for $\mathrm{Mn}$ being the controlling diffusing element for DSA, this is a 2.5 pct difference from what was measured. Thus, it may be concluded that the DSA observed in the $12 \mathrm{Mn}$ alloy is related to the interaction of $\mathrm{Mn}$ with the $\varepsilon$-martensite and austenite fault plane or interface.

A mostly austenitic microstructure was obtained during the batch anneal of the $14 \mathrm{Mn}$ alloy as shown in Figure 6. The termination energy for DSA was measured in a temperature range greater than that observed for termination of DSA in the $12 \mathrm{Mn}$ alloy and at a temperature where $\varepsilon$-martensite had completely reverted to $\gamma$-austenite or nearly so as shown in Figure 14(c). Thus, no overlap in mechanism during termination is expected for a mechanism involving $\varepsilon$-martensite. Lower onset and termination energies of $88 \pm 15$ and $155 \pm 5 \mathrm{~kJ} / \mathrm{mol}$ also differentiate the DSA mechanism from the $12 \mathrm{Mn}$ alloy. Dastur and Leslie measured onset and termination energies for DSA observed in Hadfield manganese steel and reported energies of 104 and $146 \mathrm{~kJ} / \mathrm{mol}$ with an uncertainty of 15 $\mathrm{kJ} / \mathrm{mol}$. The mechanism proposed was a complex defect with $\mathrm{Mn}$ and $\mathrm{C}$ paring close to the core of a dislocation. Using an activation energy for carbon diffusion in austenite $(134 \mathrm{~kJ} / \mathrm{mol})$ and a binding energy of 8.2 $\mathrm{kJ} / \mathrm{mol}$ for the $\mathrm{Mn}-\mathrm{C}$ bond pair as reported by Medvedeva et al. ${ }^{[25]}$ an activation energy for termination of $142 \mathrm{~kJ} / \mathrm{mol}$ is predicted. This value is a close match for that reported by Dastur and Leslie and is 9 pet lower than that measured for the $14 \mathrm{Mn}$ alloy. The onset activation energy is also reasonable and falls between that reported by Venkadesan et al. ${ }^{[35]}$ for the low titanium modified stainless steel and that reported by Dastur and Leslie. ${ }^{[20]}$ The measured onset energy of 88 $\pm 15 \mathrm{~kJ} / \mathrm{mol}$ is 0.66 that of the activation energy for carbon diffusion in $\gamma$-iron $(134 \mathrm{~kJ} / \mathrm{mol})$ suggesting that pipe diffusion of carbon along dislocations in austenite contributes to the lower activation energy for DSA than that observed in the $12 \mathrm{Mn}$ alloy. Thus, a second mechanism is proposed consistent with forming a dislocation-Mn-C complex defect in $\gamma$-austenite.

Yield point behavior and yield point elongation were observed in room temperature tensile tests of the $10 \mathrm{Mn}$ alloy. These observations would be typical of strain aging of ferritic steels associated with nitrogen. From Table II and Figure 14(a), the starting structure of the $10 \mathrm{Mn}$ alloy in the DSA initiation temperature range is 53-58 vol pet $\alpha$-ferrite, with the remainder being $\varepsilon$-martensite and $\gamma$-austenite. At strains greater than 7 pct where the onset activation energy was measured for
DSA the microstructure is a combination of $\alpha$-martensite, and $\varepsilon$-martensite as shown in Figure 9(b). An activation energy of $64 \pm 6 \mathrm{~kJ} / \mathrm{mol}$ was determined for the onset of DSA in the 10Mn alloy as shown in Figure 13(a). The observed activation energy is below that reported for carbon diffusion in pure $\alpha$-iron (82 $\mathrm{kJ} / \mathrm{mol}^{[49]}$ ); however, it is within 6 pct of the activation energy for nitrogen diffusion in pure $\alpha$-iron $(68 \mathrm{~kJ} / \mathrm{mol})$ as reported by Wert and Zener. ${ }^{[4]}$ The work by Baird and Jamieson ${ }^{[17]}$ stated that DSA associated with nitrogen in $\alpha$-ferrite was typically measured to be 63 to $84 \mathrm{~kJ} / \mathrm{mol}$ for initiation and 146 to $209 \mathrm{~kJ} / \mathrm{mol}$ for termination. The values reported in this work are a 1.5 pct relative difference from what is shown for the measured initiation energy. However, if $\mathrm{N}$ diffusion in $\alpha$-ferrite is the cause of DSA, the dominant defects are therefore dislocations and a significant contribution to work-hardening from DSA might be expected; as shown in Figure 12, this is not the case and there is only a small increase $(\sim 2$ pct $)$ in work hardening rate, and a 5 pct increase in the work hardening exponent with DSA. The small difference in work hardening rate may be attributed to the low nitrogen content expected when $\alpha$-ferrite is in equilibrium with $\gamma$-austenite as shown in Table III; as was noted earlier the concentrations reported in Table III may underestimate the $\mathrm{N}$ content of the $\alpha$-ferrite.

A termination activation energy of $123 \pm 12 \mathrm{~kJ} / \mathrm{mol}$ was measured for DSA in the $10 \mathrm{Mn}$ alloy, and the termination energy is 16 pct lower than what is reported from the work of Baird and Jamieson. ${ }^{[17]}$ Within the temperature range of termination for the $10 \mathrm{Mn}$ alloy, the microstructure is an equal proportion of $\gamma$-austenite and $\alpha$-ferrite as shown in Figure 14(a). However, the results from the $14 \mathrm{Mn}$ alloy appear fairly conclusive that $\mathrm{C}$ in $\gamma$-austenite as a DSA mechanism for the $10 \mathrm{Mn}$ alloy must be excluded, since the termination energy is well below that of carbon diffusion in austenite. Furthermore, any solute-defect mechanism for DSA that might be suggested should also carry over into the results observed at higher strains. It might be argued that the very fine serrations observed in Figure 12(b) are related to the $\mathrm{C}$-Mn-defect mechanism proposed for the $14 \mathrm{Mn}$ alloy, since there is considerable overlap in the temperature range of termination. A smaller volume fraction of $\gamma$-austenite and a finer austenite grain size may indeed reduce the magnitude of the striations that might be observed.

In comparing the DSA results of $12 \mathrm{Mn}$ to $10 \mathrm{Mn}$, the absence of $\varepsilon$-martensite, the low termination temperature range, and low termination energy for the $10 \mathrm{Mn}$ alloy lends credence to the proposed mechanism of $\mathrm{Mn}$ solute interacting with the defect structure of $\varepsilon$-martensite in the $12 \mathrm{Mn}$ alloy. It should also be noted that at temperatures greater than $523 \mathrm{~K}\left(250^{\circ} \mathrm{C}\right)$ there would be little driving force for Stage I $(\gamma \rightarrow \varepsilon)$ TRIP or standard TRIP $(\gamma \rightarrow \alpha)$ in the 10Mn alloy and as shown in Table III where the athermal Ms temperatures for transforming the austenite to martensite are $482 \mathrm{~K}$ (128 $\left.{ }^{\circ} \mathrm{C}\right)$ for the $\gamma \rightarrow \alpha$ transformation and $340 \mathrm{~K}\left(67^{\circ} \mathrm{C}\right)$ for the $\gamma \rightarrow \varepsilon$ transformation. At the test temperatures associated with termination, all of the athermal 


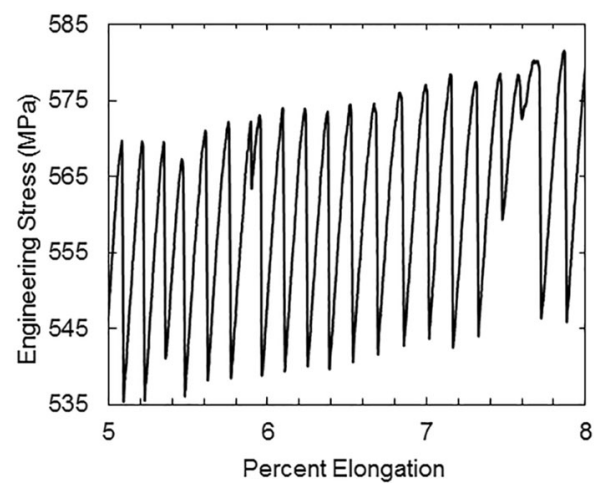

Fig. 17-The Lüders serrations from Fig. 12(a) are shown in greater detail.

$\varepsilon$-martensite has reverted to $\gamma$-austenite and this would suggest that the $M_{\mathrm{D}}$ for Stage I $(\gamma \rightarrow \varepsilon)$ TRIP or standard TRIP $(\gamma \rightarrow \alpha)$ is at lower temperature. This latter point is rationalized by viewing the $\gamma$-austenite component only and noting that the $\gamma$-austenite finish temperature is above $573 \mathrm{~K}\left(300{ }^{\circ} \mathrm{C}\right)$. However, this does not address the rather strong DSA observed at strains less than 10 pct as shown in Figure 12(a). As noted above, these striations are not associated with any stress-induced TRIP behavior and if they were, the DSA might be expected to extend to higher strains.

Two features of the DSA observed in the low strain regime of the $10 \mathrm{Mn}$ alloy must be addressed: a work hardening rate of approximately $160 \mathrm{MPa}$ and a large oscillation amplitude that is greater than $30 \mathrm{MPa}$. Both observations might be explained by the formation of mechanical twins in the austenite. A calculation of the ISF energy at $573 \mathrm{~K}\left(300{ }^{\circ} \mathrm{C}\right)$ for the austenite chemistry yields $42.0 \mathrm{~mJ} / \mathrm{m}^{2}$ and this value is within a range that might be expected to produce twin induced plasticity or TWIP. It is generally accepted that Mn steels with an ISF energy $\geq 20 \mathrm{~mJ} / \mathrm{m}^{2}$ preferentially exhibits twin formation instead of martensitic transformation. A portion of the stress-strain response showing the detail of the serrations is shown in Figure 17. Initiation of the twining process occurs in a favorably oriented austenite grain and this would occur at a threshold stress for twin nucleation. Mechanical twins are capable of producing large strains and as a result of conducting the test in displacement or strain control the required load would drop precipitously until the twin extends across the austenite grain. The reader is again reminded that the $\gamma$-austenite grains are submicron and dispersed with ferrite grains. Thus, the TWIP may be restricted to a single twin within the grain and deformation of one $\gamma$-austenite grain may not sympathetically nucleate mechanical twins in neighboring $\gamma$-austenite grains. A stress rise occurs as the first twin reaches a terminal length and the imposed displacement rate must be accommodated by dislocation plasticity until the next most favorably oriented austenite grain undergoes twin deformation. This process is repeated to $\sim 10$ pct strain which appears to be the saturation point for twinning in this microstructure. The authors wish to reiterate that the systems investigated are extremely complex and there is much more investigation required to fully understand these medium-Mn steels. It may now be concluded that the DSA observed in the 10Mn alloy is associated with $\mathrm{N}$ in $\alpha$-ferrite and that the higher termination energy measured by Baird and Jamieson ${ }^{[17]}$ may be a combined mechanism of both carbon and nitrogen DSA occurring in a fully $\alpha$-ferrite microstructure.

Also reported in this study are tensile properties for hot band and intercritically annealed materials having first been cold worked. The $14 \mathrm{Mn}$ alloy is the only hot-band steel investigated that exhibits a strain-induced transformation sequence within the criteria of a typical two-stage TRIP response as reported in the literature. ${ }^{[13]}$ There is an initial increase in $\varepsilon$-martensite associated with the $\gamma \rightarrow \varepsilon$ Stage I transformation occurring at low strains $(\leq 4$ pct $)$ and once the system is saturated with $\varepsilon$-martensite and all of the $\gamma$-austenite is consumed, Stage II $\varepsilon \rightarrow \alpha$, transformation occurs to failure as shown in Figure 9. The strain levels associated with the transition of Stage I to Stage II are consistent with the works described by both Shin et al. ${ }^{[52]}$ and Huang et al. $^{[53]}$ from their works on ferrous shape memory alloys that contain $\varepsilon$-martensite. It was shown that beyond 4 pct strain the deformation was unrecoverable due to the formation of $\alpha$-martensite from the intersection of $\varepsilon$-martensite bands. From Figures 8 and 9, it can be seen that the initial low work hardening region is associated with the first martensitic transformation of $\gamma$-austenite to $\varepsilon$-martensite. The elevated work hardening portion of the stress-strain graph is shown from the XRD results to be the second martensitic transformation of $\varepsilon$-martensite to $\alpha$-martensite and exhibits an average work hardening rates $>3300 \mathrm{MPa}$.

\section{CONCLUSION}

The Cr-modified $12 \mathrm{Mn}$ alloy was found to be a two-stage TRIP steel with a significantly reduced DSA response during tensile testing. The reduction in DSA was attributed to the formation of $\mathrm{M}_{23}(\mathrm{C}, \mathrm{N})_{6}$. The Cr-modified $12 \mathrm{Mn}$ alloy had a significantly higher activation energy for the onset of DSA which was measured to be $145 \pm 14 \mathrm{~kJ} / \mathrm{mol}$, and DSA in the $12 \mathrm{Mn}$ alloy was related to $\mathrm{Mn}$ positioning within the fault structure of the $\varepsilon$-martensite austenite interface based upon the high termination energy of $277 \pm 8 \mathrm{~kJ} / \mathrm{mol}$. The DSA mechanism in the $14 \mathrm{Mn}$ is differentiated from the $12 \mathrm{Mn}$ steel and is attributed to $\mathrm{C}$ diffusion in $\gamma$-austenite with the added binding energy for the dislocation-Mn-C bond pairing. The activation energy and termination energies for DSA in the $10 \mathrm{Mn}$ steel were found to be interstitial nitrogen trapping at dislocations within the $\alpha$-ferrite. The $14 \mathrm{Mn}$ steel was the only alloy in the hot band condition that exhibited the two-stage TRIP phenomenon. After batch annealing at $873 \mathrm{~K}\left(600{ }^{\circ} \mathrm{C}\right)$ for 20 hours, all three investigated steels demonstrate a two-stage TRIP behavior. This is observed by an initial saturation of the system with $\varepsilon$-martensite by consuming some of the retained 
$\gamma$-austenite, and concludes with the formation of $\alpha$-martensite from the transformation of $\varepsilon \rightarrow \alpha$.

\section{ACKNOWLEDGMENTS}

This work was supported by the Peaslee Steel Manufacturing Research Center (PSMRC). Companies directly involved in this work include AK Steel, ArcelorMittal, Nucor Steel, and U. S. Steel. The FEI Helios NanoLab dual beam FIB was obtained with a Major Research Instrumentation grant from the National Science Foundation under contract DMR0723128. The authors also acknowledge the support of the Materials Research Center and in particular Dr. Clarissa Wisner and Dr. Jingjing Qing for guidance and training on the SEM as well as Dr. Eric Bohannan for performing the XRD work. Special thanks are also extended to Dr. Narayan Pottore and Dr. Shrikant Bhat at ArcelorMittal for their discussions on DSA mechanisms.

\section{REFERENCES}

1. T. Tschiyama, T. Inoe, J. Tobata, D. Akami, and S. Takaki: Scr. Mater., 2016, vol. 122, pp. 36-39.

2. D.-W. Suh, S.-J. Park, T.-H. Lee, C.-S. Oh, and S.-J. Kim: Metall. Mater. Trans. A, 2010, vol. 41A, pp. 397-408.

3. D.-W. Suh, J.-H. Ryu, M.-S. Joo, H.-S. Yang, and H.K.D.H. Bhadeshia: Mater. Trans. A, 2013, vol. 44A, pp. 286-93.

4. J. Shi, X. Sun, M. Wang, W. Hui, H. Dong, and W. Cao: Scr. Mater., 2010, vol. 63, pp. 815-18.

5. H. Luo, H. Dong, and M. Huang: Mater. Des., 2015, vol. 83, pp. $42-48$

6. S. Lee, S.-J. Lee, S. Santhosh Kumar, K. Lee, and B.C. De Cooman: Metar. Trans. A, 2011, vol. 42A, pp. 3638-51.

7. Y. Zhang, L. Wang, K.O. Findley, and J. Speer: Metar. Trans. A, 2017, vol. 48A, pp. 2140-49.

8. J. Han, S.-H. Kang, S.-J. Lee, and Y.-K. Lee: J. Alloy. Compound., 2016, vol. 681, pp. 580-88.

9. J. Han, S.-J. Lee, J.-G. Jung, and Y.-K. Lee: Acta Mater., 2014, vol. 78, pp. 369-77.

10. P.J. Gibbs, E. De Moor, M.J. Merwin, B. Clausen, J.G. Speer, and D.K. Matlock: Metar. Trans. A, 2011, vol. 42A, pp. 3691-3701.

11. A. Arlazarov, M. Goune, O. Bouaziz, A. Hazotte, G. Petigand, and P. Barges: Mater. Sci. Eng. A, 2012, vol. 545, pp. 31-39.

12. D.M. Field and D.C. Van Aken: Metar. Trans. A, 2016, vol. 47A, pp. 1912-17.

13. M.C. McGrath, D.C. Van Aken, N.I. Medvedeva, and J.E. Medvedeva: Metall. Mater. Trans. A, 2013, vol. 44A, pp. 4634-43.

14. C.D. Horvath, C.M. Enloe, J.P. Singh, and J.J.Coryell: Intl. Symp. On New Developments in AHSS, "Persistent Challenges to Advanced High-Strength Steel Implementation" Keystone, CO. 2017.

15. J.F. Enrietto: J. Iron Steel Inst., 1966, vol. 12, pp. 252-58.

16. W. Wepner: Arch. Eisenh., 1955, vol. 22, pp. 71-81.

17. J.D. Baird and A. Jamieson: J. Iron Steel Inst., 1966, vol. 204, pp. $793-801$.
18. K. Steineder, D. Krizan, R. Schneider, C. Béal, and C. Sommitsch: Acta Mater., 2017, vol. 139, pp. 39-50.

19. P. Rodriguez: Bull. Mater. Sci., 1984, vol. 6, pp. 653-63.

20. Y.N. Dastur and W.C. Leslie: Metar. Trans. A, 1981, vol. 12, pp. $749-59$.

21. S.-J. Lee, J. Kim, S.N. Kane, and B.C. De Cooman: Acta Mater., 2011, vol. 59, pp. 6809-19.

22. R.W. Balluffi: Phys. Status Solidi, 1970, vol. 41, pp. 11-21.

23. M. Kuzmina, M. Herbig, D. Ponge, S. Sandlöbes, and D. Raabe: Science, 2015, vol. 349, pp. 1080-83.

24. N.I. Medvedeva, D.C. Van Aken, and J.E. Medvedeva: J. Phys. Condens. Matter, 2010, vol. 22, p. 316002.

25. N.I. Medvedeva, M.S. Park, D.C. Van Aken, and J.E. Medvedeva: J. Alloy. Compd., 2014, vol. 582, pp. 475-82.

26. J.B. Seol, J.E. Jung, Y.W. Jang, and C.G. Park: Acta Mater., 2013, vol. 61 , pp. 558-78.

27. X.G. Wang, L. Wang, and M.X. Huang: Acta Mater., 2017, vol. 124, pp. 17-29.

28. B. Sun, N. Vanderesse, F. Fazeli, C. Scott, J. Chen, P. Bocher, M. Jahazi, and S. Yue: Scr. Mater., 2017, vol. 133, pp. 9-13.

29. M. Callahan, O. Hubert, F. Hild, A. Perlade, and J.-H. Schmitt: Mater. Sci. Eng. A, 2017, vol. 704, pp. 391-400.

30. D. Lee, J.-K. Kim, S. Lee, K. Lee, and B.C. De Cooman: Mater. Sci. Eng. A, 2017, vol. 706, pp. 1-14.

31. B.K. Choudhary, K.B.S. Rao, S.L. Mannan, and B.P. Kashyap: Mater. Sci. Technol., 1999, vol. 15, pp. 791-97.

32. B.K. Choudhary: Mater. Sci. Technol., 2013, vol. 29, pp. 278-84.

33. B.K. Choudhary: Mater. Sci. Technol., 2013, vol. 29, pp. 303-09.

34. B.K. Choudhary, E.I. Samuel, G. Sainath, J. Christopher, and M.D. Mathew: Metar. Trans. A, 2013, vol. 44A, pp. 4979-92.

35. S. Venkadesan, C. Phaniraj, P.V. Sivaprasad, and P. Rodriguez: Acta Metall. Mater., 1992, vol. 40, pp. 569-80.

36. L.J. Cuddy and W.C. Leslie: Acta Metar., 1972, vol. 20, pp. 1157-67.

37. K.T. Park, K.G. Jin, S.H. Han, S.W. Hwang, K. Choi, and C.S. Lee: Mater. Sci. Eng. A, 2010, vol. 527, pp. 3651-61.

38. J. Kim, S.J. Lee, and B.C. De Cooman: Scripta Materialia, 2011, vol. 65 , pp. 363-66.

39. P.G. McCormick: Acta Metall., 1972, vol. 20, pp. 351-54.

40. A.W. Sleeswyk: Acta Metall., 1958, vol. 6, pp. 598-603.

41. K.R. Limmer, J.E. Medvedeva, D.C. Van Aken, and N.I. Medvedeva: Comput. Mater. Sci., 2015, vol. 99, pp. 253-55.

42. D.M. Field, D.S. Baker, and D.C. Van Aken: Metar. Trans. A, 2017, https://doi.org/10.1000/s11661-017-4020-2.

43. S.T. Pisarik and D.C. Van Aken: Metar. Trans. A, 2016, vol. 47A, pp. 1009-18.

44. G.B. Olson and M. Cohen: Metar. Trans. A, 1976, vol. 7, pp. 1897-1904.

45. ASTM E 8/E 8M-08, Standard Test Methods for Tension Testing of Metallic Materials.

46. S. Martin, C. Ullrich, D. Simek, U. Martin, and D. Rafaja: $J$. Appl. Crystallogr., 2011, vol. 44, pp. 779-87.

47. S.T. Pisarik and D.C. Van Aken: Metar. Trans. A., 2014, vol. 45, pp. 3173-78.

48. C.C. Kinney, I. Yi, K.R. Pytlewski, A.G. Khachaturyan, N.J. Kim, and J.W. Morris, Jr: Acta Mater., 2017, vol. 125, pp. 442-54.

49. C. Wert and C. Zener: Phys. Rev., 1949, vol. 76, pp. 1169-75.

50. C. Wells and R.F. Mehl: Metar. Technol., 1941, vol. 145, p. 1282.

51. K. Oi, C. Lux, and G.R. Purdy: Acta Mater., 2000, vol. 48, pp. $2147-55$.

52. S. Shin, M. Kwon, W. Cho, I.S. Suh, and B.C. De Cooman: Mater. Sci. Eng., 2017, vol. 683, pp. 187-194.

53. S.K. Huang, Y.H. Wen, N. Li, J. Teng, S. Ding, and Y.G. Xu: Mater. Charact., 2008, vol. 59, pp. 681-87. 